\title{
Evolution of tribologically induced chemical and structural degradation in hydrogenated a-C coatings
}

\author{
Roman Nevshupa 1,* , Jaume Caro 2, Alba Arratibel ${ }^{3}$, Raül Bonet ${ }^{2}$, Anton Rusanov 4,5 , Jose \\ Ramon Ares ${ }^{6}$ and Elisa Roman ${ }^{7}$ \\ 1 Spanish National Research Council, “Eduardo Torroja” Institute (IETCC-CSIC), Madrid 28033, Spain; \\ r.nevshupa@csic.es \\ 2 Fundació CTM Centre Tecnològic, Manresa 08243, Spain; jaume.caro@ctm.com.es; raul.bonet@ctm.com.es \\ 3 Tecnalia, Donostia-San Sebastián 20009, Spain; alba.arratibel@tecnalia.com \\ 4 Laboratoire de Tribologie et Dynamique des Systèmes, Ecole Centrale de Lyon, UMR 5513, 69134 Ecully \\ Cedex, France; anton.rusanov@yahoo.fr (Present affiliation : Altran AG, CH-1005 Lausanne) \\ 5 Bauman Moscow State Technical University, Moscow 105005, Russia \\ ${ }^{6}$ Group Materials of Interest for Renewable Energies (MIRE), Autonoma University of Madrid, Madrid \\ 28049, Spain, joser.ares@uam.es \\ 7 Spanish National Research Council, Institute of Material Sciences of Madrid (ICMM-CSIC), Madrid 28049, \\ Spain; eromangarcia@hotmail.com \\ * Correspondence: r.nevshupa@csic.es; Tel.: +34-91-302-0440
}

Academic Editor: name

Received: date; Accepted: date; Published: date

\begin{abstract}
The coatings with gradually varying chemical composition and structure were obtained by PECVD method from methane precursor and various admixtures of Ar. The composition of emitted gases and triboemission behaviour were studied for these coatings and correlated with the coating properties and deposition conditions. A new analytical approach was developed that allowed identification of the emitted gas species with much higher accuracy. For the first time, triboemission of alkanes higher than propane was observed. By the application of kinetic model to the analysis of triboemission time series, chemical and structural degradation in carbon coatings could be traced in course of tribological tests.
\end{abstract}

Keywords: hydrogenated amorphous carbon; degradation; tribochemistry; mass-spectrometry

\section{Introduction}

Amorphous carbon (a-C) coatings serve in widespread tribological applications to improve wear resistance and to reduce friction. Mechanical and tribological properties of a-C can be flexibly tailored by varying $s p^{2}$ to $s p^{3}$ ratio, hydrogen concentration and doping elements [1]. Aijaz et al. [2] demonstrated that the electron density and/or temperature in plasma are the key factor to turn physical properties, composition and chemistry of a-C. The control of these parameters can be achieved by adjusting the concentration and composition of the precursor gases. The addition of argon, neon or other heavy gases to the process gas results in modification of the chemical bonding of carbon, changing hydrogen and nanovoids distribution in the coating, and trapping inert gases in the coating $[2,3]$.

Among various a-C classes hydrogenated amorphous carbon $(\mathrm{a}-\mathrm{C}: \mathrm{H})$ has attracted much attention since the discovery of its near-frictionless and near-wearless properties under vacuum or inert atmosphere [4]. A large amount of research has been conducted to gain molecular-level understanding of advanced tribological properties of a-C:H and the mechanisms of their degradation [5-12]. It was found that ultra-low friction regime usually sets in after a run-in period, during which a thin modified surface layer on the coating and a transfer film on a counterbody evolve. The transfer film results from formation and breaking of covalent bonds [13]. The transfer film, the debris, and the modified surface layer tend to have higher $s p^{2}$ bonding $[14,15]$ that is associated with hydrogen loss and graphitization of metastable $s p^{3}$ bonds $[16,17]$. High hydrogen content has a significant effect on 
reduction of friction and wear rates due to passivation of dangling bonds and suppression of C-C bonds formation across the interface $[6,8,13,15,18-20]$. Furthermore, repulsive electrostatic forces [21] at hydrogen-terminated surfaces reduce adhesion, while tribochemical generation of dihydrogen molecules at the sliding interface enlarges the distance between the surfaces because of the steric effect [18]. It was also demonstrated that the coating failure relies on the hydrogen depletion in it, and that this process is reversible [22].

Despite the efforts made to elucidate the a-C:H degradation, understanding of its tribochemical bases is still a challenging task. The main difficulty in studying tribological and associated tribophysical and tribochemical phenomena is the technical limitation for in situ characterization of increasingly complex physical and chemical processes on micro- and macroscales interfaces. Although combination of certain surface characterization techniques with the tribological ones has been an important advancement that afforded the opportunity to trace plastic flow, fracture, formation and cleavage of chemical bonds, excitation of vibrational and electronic states, etc. at the contact zone [23-27], the combined techniques have a number of geometry, materials and environment constrains. A new technique based on the analysis of Mechanically Stimulated Gas Emission (MSGE) has been developed recently [28-30]. The main advantage of this technique, MSGEMass Spectrometry (MSGE-MS), is that it allows analyzing the evolution of tribochemical and structural processes occurring in a buried interface. MSGE-MS has been a further improvement of in situ mass-spectrometry coupled with a tribological experimental set-up [31-38], which was successively applied to the exploratory research of tribochemical degradation and gas triboemission from various types of a-C and a-C:H [39-41]. These studies showed that the main emitted gas species from a-C:H were methane and hydrogen. Traces of $\mathrm{CO}, \mathrm{H}_{2} \mathrm{O}$, ethane, propane and $\mathrm{CO}_{2}$ with undetermined proportions were also observed [39, 42]. Triboemission of various gas species showed a complex behaviour, which could be linked to either friction or wear [43]. For example, Ar emission seemed to correlate with plastic deformation and fracture. In turn, $\mathrm{H}_{2}$ and $\mathrm{CH}_{4}$ triboemission showed more complex behaviours with the emission rate being nearly parabolic function of $\mathrm{H}$ content [40]. It was suggested that both $\mathrm{H}_{2}$ and $\mathrm{CH}_{4}$ triboemission rely on tribochemical processes [41]. All researches discarded frictional heating as the driving force for gas triboemission under mild sliding conditions $[17,42]$.

The main objective of this work is to study evolution of structural and chemical degradation under sliding for a series of a-C:H coatings through the analysis of gas triboemission time series using MSGE-MS. The coatings were obtained using PECVD method with varying Ar/methane ratios in the precursor gases. Tribological and triboemission characteristics of a-C:H coatings were correlated with their physico-chemical properties and deposition conditions. Better time resolution of mass-spectra in comparison with the previous works and a new data analysis method based on behavioural analysis, linear regression fitting and statistical hypothesis testing allowed us to identify the emitted gas species more accurately. The possible tribochemical processes leading to the $\mathrm{H}_{2}$ and hydrocarbons triboemission were discussed. The evolution of structural degradation was traced through the analysis of Ar emission using a kinetic triboemission model.

\section{Materials and Methods}

Amorphous carbon coatings were deposited on polished AISI 420 stainless steel substrates using pulsed Plasma Enhanced Chemical Vapour Deposition (PECVD). Argon/methane mixtures with flow proportions: 18.9/81.1, 6.8/93.2 and 0/100 were used as a process gas for the coatings D-050, D-051 and D-052, correspondingly. A pulsed bias of $-1000 \mathrm{~V}$, frequency $30 \mathrm{kHz}$ and duty cycle $27 \%$ was applied to the substrates during deposition. Substrate temperature was $20^{\circ} \mathrm{C}$. Deposition time was kept at 60 minutes for all samples (Table 1).

In a complementary Ar triboemission from a coating obtained by Ion Beam Deposition (IBD) technique was studied. The coating was identical to D-2 in [39]. The coating was deposited on a silicon substrate from two ion sources fed by cyclohexane and argon, respectively. The ratio argon/cyclohexane was 33/67. 
Table 1. Deposition parameters and properties of a-C:H processed samples.

\begin{tabular}{ccccc}
\hline Sample & Gas pressure $(\mathbf{P a})$ & $\mathrm{Ar} / \mathrm{CH}_{4}$ ratio & Film thickness $(\mu \mathrm{m})$ & Hardness $(\mathrm{GPa})$ \\
\hline D-050 & 8 & $18.9 / 81.1$ & 0.70 & $19.5 \pm 3.2$ \\
D-051 & 10 & $6.8 / 93.2$ & 0.65 & $22.2 \pm 2.7$ \\
D-052 & 10 & $0 / 100$ & 1.50 & $20.8 \pm 1.9$ \\
\hline
\end{tabular}

Gas triboemission from the materials was characterized using the original technique MSGE-MS [29], which combines the following essential components: a specially designed ultrahigh vacuum reciprocating motion friction cell with near-zero intrinsic triboemission, a dynamic expansion system for quantification of minute $(<1 \mathrm{nmole} / \mathrm{s})$ gas emission rates, and a mass-spectrometer. An alumina ball with the diameter $2 \mathrm{~mm}$ was used as a counterbody. Normal load ranged between $0.86 \mathrm{~N}$ and $2.13 \mathrm{~N}$, while sliding speed was $0.18-0.4 \mathrm{~m} / \mathrm{s}$. Several mass-spectrometer channels corresponding to ions with different mass-to-charge ratio, $\mathrm{m} / \mathrm{z}$, were measured during rubbing and after its end in order to determine the variations related with mechanical activation of the sample. The background measured before the beginning of rubbing was subtracted from each signal. The resulting time series, i.e. differential mass-spectrometer (DMS) signals, were analyzed following previously described procedure [44]. If the ion current increase during rubbing was not statistically significant at significance level 0.05 , the corresponding channel was eliminated from further examination.

Friction force could not be measured simultaneously with the gas emission because of cross-talk interference between the force gauges and the analytical equipment (the pressure gauges and the mass-spectrometer). Therefore, a separate series of experiment was conducted to measure friction force under vacuum using ultrahigh vacuum tribometer $\mathrm{Ca}^{3} \mathrm{UHV}$ [29] with reciprocating motion pinon-flat configuration. A boron glass ball, $3 \mathrm{~mm}$ in diameter, was a counterbody. The maximum sliding velocity and acceleration were $60 \mathrm{~mm} / \mathrm{s}$ and $15 \mathrm{~mm} / \mathrm{s}^{2}$, correspondingly. The sliding distance was $2 \mathrm{~mm}$ and the number of sweeps in each test was 400 . Three repeated tests were done with the normal loads $1.96 \mathrm{~N}, 4.91 \mathrm{~N}$ and $9.81 \mathrm{~N}$.

Chemical composition of the coatings was characterized using Elastic Recoil Detection Analysis (ERDA) and Rutherford Backscattering Spectrometry (RBS) with $\mathrm{He}^{+}$beam of $3 \mathrm{MeV}$ energy. Monoor bilayer coating models were developed and fitted to the experimental data by means of the Simplex algorithm using SIMNRA software [45]. Raman spectrometry and Attenuated Total Reflection Fourier-Transformed Infrared (ATR-FTIR) spectrometry were used to study chemical bonding in the coatings. The hardness of the coatings was measured by means of instrumented nanoindentation technique.

\section{Results}

\subsection{Mechanically stimulated gas emission}

\subsubsection{Emission behaviours}

An initial exploratory test was carried out on each sample. In this test the ion time series with $\mathrm{m} / \mathrm{z}$ from 1 to 100 were measured during rubbing, before its beginning and after its end. A previously developed statistical method [44] was used to sift through the measured data and to rule out the signals, whose response to rubbing was not statistically significant (in comparison with the background noise) at the critical level 0.05 . The statistically significant channels are listed on Table 2 .

Previous works showed that the assignment of the ion species to molecular or radical precursors can be facilitated if the channels are grouped according to their behaviour patterns [40, 44, 46]. For this purpose, the behavioural analysis was carried out. Figure 1 shows the representative plots of the selected ions time series, in which three behavioral patterns are clearly noted. The first one, denoted $\lambda$, applies to $\mathrm{m} / z 20$ and 40, which were ascribed to $\mathrm{Ar}^{++}$and $\mathrm{Ar}^{+}$, respectively. It is characterized by two stages. In the first stage (1a in Figure 1 (a)) a burst with a sharp rise occurred just at the beginning of rubbing. Then, the emission rate decreased nearly linearly with time. The first stage lasted about 200 rubbing cycles (100 s). The second stage came out after a short transition and was characterized 
by a series of chaotic bursts ( $2 a$ in Figure 1 (a)). Mean emission rate in the second stage was nearly twice as high as in the first stage. When the rubbing stopped, the mass-spectrometer signal almost immediately returned to the background level. The transition time was limited by the pumping rate of the vacuum system (time constant for Ar $2.3 \mathrm{~s}$ ).

Table 2. The mass-spectrometer channels selected from the initial exploratory tests, the possible ionized species corresponding to each channel and the possible precursor molecules

\begin{tabular}{|c|c|c|c|}
\hline$m / z$ & Behaviour pattern & Possible ions & Possible emitted gases \\
\hline 2 & $\sigma_{1}$ & $\mathrm{H}_{2}^{+}$ & $\mathrm{H}_{2}$ \\
\hline 14,15 & $\mu$ & $\mathrm{CH}_{2}{ }^{+}, \mathrm{CH}_{3}{ }^{+}$ & $\mathrm{CH}_{4}, \mathrm{C}_{x} \mathrm{H}_{\mathrm{y}}(\mathrm{x}>1)$ \\
\hline 16 & $\mu$ & $\mathrm{CH}_{4}{ }^{+}, \mathrm{O}^{+}$ & $\mathrm{CH}_{4}, \mathrm{CO}, \mathrm{CO}_{2}$ \\
\hline 20,40 & $\lambda$ & $\mathrm{Ar}^{++}, \mathrm{Ar}^{+}$ & $\mathrm{Ar}$ \\
\hline $26,27,29,30$ & $\mu$ & $\mathrm{C}_{2} \mathrm{H}_{2}{ }^{+}, \mathrm{C}_{2} \mathrm{H}_{3}{ }^{+}, \mathrm{C}_{2} \mathrm{H}_{5}{ }^{+}, \mathrm{C}_{2} \mathrm{H}_{6}{ }^{+}$ & $\mathrm{C}_{2} \mathrm{H}_{6}, \mathrm{C}_{3} \mathrm{H}_{8}, \mathrm{C}_{4} \mathrm{H}_{10}$ \\
\hline 28 & $\mu$ & $\mathrm{C}_{2} \mathrm{H}_{4}^{+}, \mathrm{CO}^{+}$ & $\mathrm{C}_{2} \mathrm{H}_{6}, \mathrm{C}_{3} \mathrm{H}_{8}, \mathrm{C}_{4} \mathrm{H}_{10}, \mathrm{CO}, \mathrm{CO}_{2}$ \\
\hline $41,42,43,45$ & $\mu$ & $\mathrm{C}_{3} \mathrm{H}_{5}{ }^{+}, \mathrm{C}_{3} \mathrm{H}_{6}{ }^{+}, \mathrm{C}_{3} \mathrm{H}_{7^{+}}$, & $\mathrm{C}_{3} \mathrm{H}_{8}, \mathrm{C}_{4} \mathrm{H}_{10}, \mathrm{CH}_{3} \mathrm{OCH}_{3}(?)$ \\
\hline 44 & $\mu$ & $\mathrm{C}_{3} \mathrm{H}_{8^{+}}, \mathrm{CO}_{2}^{+}$ & $\mathrm{C}_{3} \mathrm{H}_{8}, \mathrm{C}_{4} \mathrm{H}_{10}, \mathrm{CO}_{2}$ \\
\hline
\end{tabular}
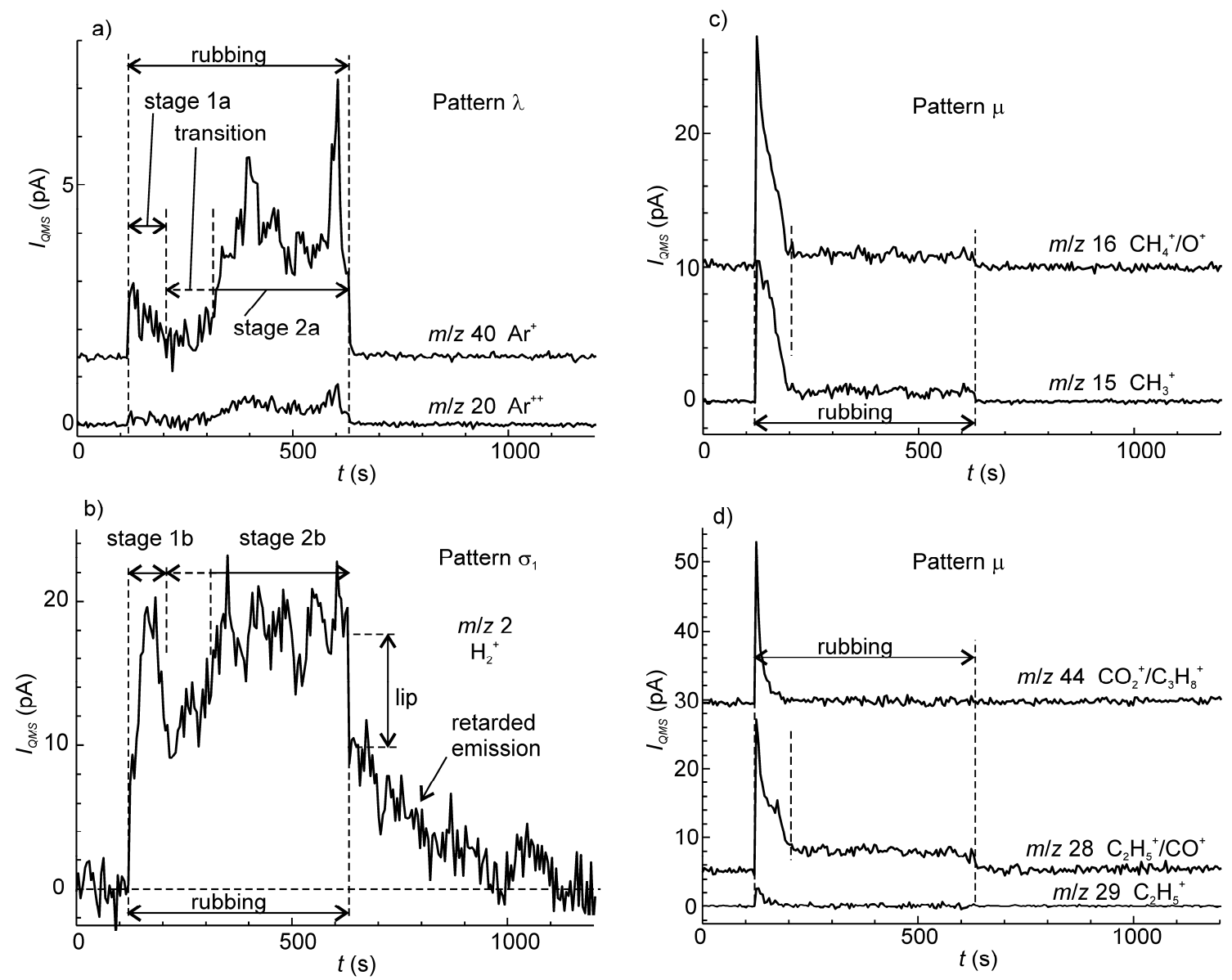

Figure 1. The representative time series of mass-spectrometer channels with different mass-to-charge ratios, $m / z$ : (a) hydrogen ions; (b) argon ions; (c) methane, methyl and atomic oxygen ions; (d) C2 and C3 alkyl ions, carbon mono- and dioxide ions.

A good linear correlation between the channels at $\mathrm{m} / \mathrm{z} 20$ and 40 was observed: adjusted coefficient of determination, $R^{2}$ adj, was 0.8355 and 0.6596 for D-050 and D-051, correspondingly. The ratio $I_{Q M S}(20) / I_{Q M S}(40)$ was determined from the slope of the linear fit (Figure 2 (a)). The difference between the measured ratio 0.142 (standard error 0.007) and the standard value from the NIST 
database 0.1462 [47] was not statistically significant (the null hypothesis was accepted with the $p$ value $=0.546$ ). This result backs up our assignment of the ions with $\mathrm{m} / \mathrm{z} 20$ and 40 to doubly and singly ionized Ar. The reasons of the complex two-stage behaviour of Ar triboemission will be discussed below.
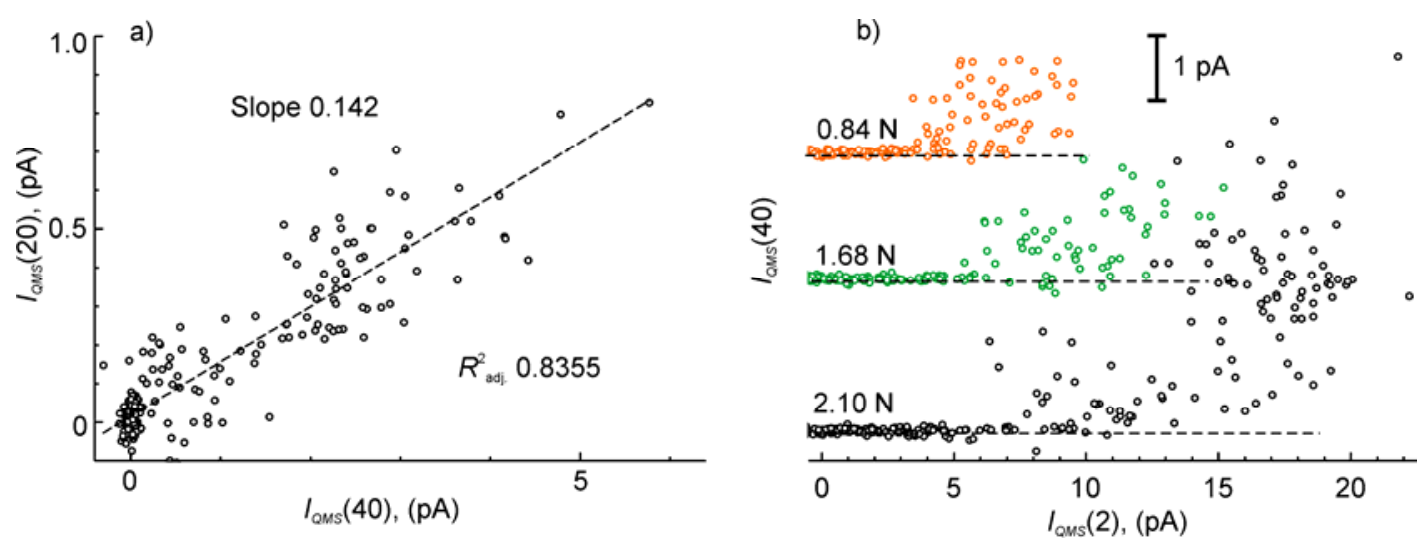

Figure 2. Correlation plots of mass-spectrometer channels: (a) The ion time series with $\mathrm{m} / \mathrm{z} 20$ as function of the ion time series with $m / z 40$ for D-050, normal load $2.10 \mathrm{~N}$; (b) The ion time series with $m / z 40\left(\mathrm{Ar}^{+}\right)$as function of the ion time series with $m / z 2\left(\mathrm{H}_{2}{ }^{+}\right)$for D-050 at three levels of the normal load noted at the plots. The plots are vertically shifted. The zero of each plot is shown by a horizontal dashed line.

The behaviour of the ion time series with $m / z 2\left(\mathrm{H}_{2}+\right)$ shown in Figure 1 (b) might seem at first glance similar to $\lambda$ pattern. However, a closer examination reveals a number of significant behavioural differences between the channels at $m / z 40$ (pattern $\lambda$ ) and $m / z 2$ (pattern $\sigma_{1}$ ). In fact, for $\sigma_{1}$ the ratio of intensities of the first and the second stages was significantly higher than for $\lambda$; and $\sigma_{1}$ showed a slowly decaying retarded emission after the rubbing end, which was not observed in $\lambda$. The lack of correlation between the two channels is evident in Figure $2(b)$, where the ion current $I_{Q M S}(m / z 40)$ is plotted against $I_{Q M S}(m / z 2)$. This finding is in line with the previous results, which put triboemission of $\mathrm{H}_{2}$ and Ar down to different basic mechanisms [41], but below we will show that the $\mathrm{H}_{2}$ triboemission can also be attributed to two or more emission sources, which were activated with a time lag.

The channels with $\mathrm{m} / \mathrm{z}$ other than 2, 20 and 40 behaved following the pattern denoted $\mu$ (Figure 1 (c) and (d)), which is characterized by a sharp burst in the first stage and a low-level steady triboemission in the second one. Triboemission ceased almost instantly after the rubbing end. These channels can be ascribed to ions of various hydrocarbons, carbon mono- and dioxide, which are typically observed in mass-spectra of gases emitted from various carbon materials under mechanical activation, heating, laser ablation, etc. [39-41, 48, 49].

\subsubsection{Identification of the gas species}

The composition of the emitted gases can be figured out from a mass-spectrum by solution of a system of linear equations if the standard mass-spectra of each component are known. However, straightforward application of this approach to raw triboemission data has not been effective so far because of significant data scattering that led to large dispersion of the results and low strength of evidence against the null hypothesis ( $H_{0}$ : the concentration of a given gas in the mixture is zero). A different approach implies time averaging of the data through pair-wise fitting of a linear regression model to the mass-spectrometer channels. The ratio of intensities of each pair of the channels were determined from the slopes of the corresponding linear regression lines. This significantly reduced the dispersion of results, but could only be applied to the signals, which are linearly correlated.

The representative examples of pair-wise regression for $I_{Q м s(14)}$ vs. $I_{Q м S}(16)$ and $I_{Q м s(15)}$ vs. $I_{Q \mathrm{QS}}(16)$ are shown in Figure 3. These channels have strong linear relationship with the $R^{2}$ adj. $>0.8184$ 
for all three samples and applied loads. Considering previous studies [39-41], this led us to assign them tentatively to the ions $\mathrm{CH}_{2}{ }^{+}, \mathrm{CH}_{3}{ }^{+}$and $\mathrm{CH}_{4}{ }^{+}$, which come mainly from methane. The $\mathrm{CH}_{2}, \mathrm{CH}_{3}{ }^{+}$ may have some minor contribution from higher hydrocarbons. To check the correctness of the ion assignment, the slopes of linear regressions $I_{Q M S}(15) / I_{Q M S}(16)$ were compared with the standard ratio of these components from methane mass-spectrum [47] (Figure 4 (a)). For D-052 the null hypothesis ( $H_{0}$ : the measured ratio is equal to the standard one) was accepted for all normal loads ( $p$-values $>$ $0.205)$, but for D-051 and D-050 $H_{0}$ was rejected ( $p$-values $<0.03$ ) for all loads except for D-051 under $F_{N}=0.84 \mathrm{~N}$ since the measured slopes $I_{\mathrm{QMS}}(15) / I_{\mathrm{QMS}}(16)$ were significantly smaller than the standard ratio. This finding is quite surprising and antithetic to the earlier works [40,41], in which the measured ratio $I_{\mathrm{QMS}}(15) / I_{\mathrm{QMS}}(16)$ was equal to or even slightly higher than the standard one, that was related to the possible emission of unrecombined methyl radicals through tribochemical bond scission. However, this study reveals a virtual shortage of $\mathrm{CH}_{3}{ }^{+}$ions or an excess of $\mathrm{CH}_{4}{ }^{+}$ions. The difference between the measured and the standard $I_{Q M S}(15) / I_{Q M S}(16)$ ratios increased with increasing $\mathrm{Ar} / \mathrm{methane}$ ratio in the process gas. This mismatch cannot be explained by the contribution from any other possible isotopically unsubstituted hydrocarbon molecules or radicals, since all of them yield much higher proportion of the ions with $m / z$ 15, than with $m / z 16$ (see Appendix A). This has led us to the conclusion that besides $\mathrm{CH}_{4}{ }^{+}$, some different ionic species with $\mathrm{m} / z 16$ must exist. This species is most likely the $\mathrm{O}^{+}$coming from cracking of $\mathrm{CO}_{2}$ and to a smaller extent of $\mathrm{CO}$ according to the relative abundances of $\mathrm{O}+$ in the mass-spectra of $\mathrm{CO}_{2}$ and $\mathrm{CO} 0.096$ and 0.017 , correspondingly. Water as a source of $\mathrm{O}^{+}$was discarded because of the lack of its main cracking components: $\mathrm{H}_{2} \mathrm{O}^{+}$and $\mathrm{OH}^{+}$ with $m / z 18$ and 17 , respectively.

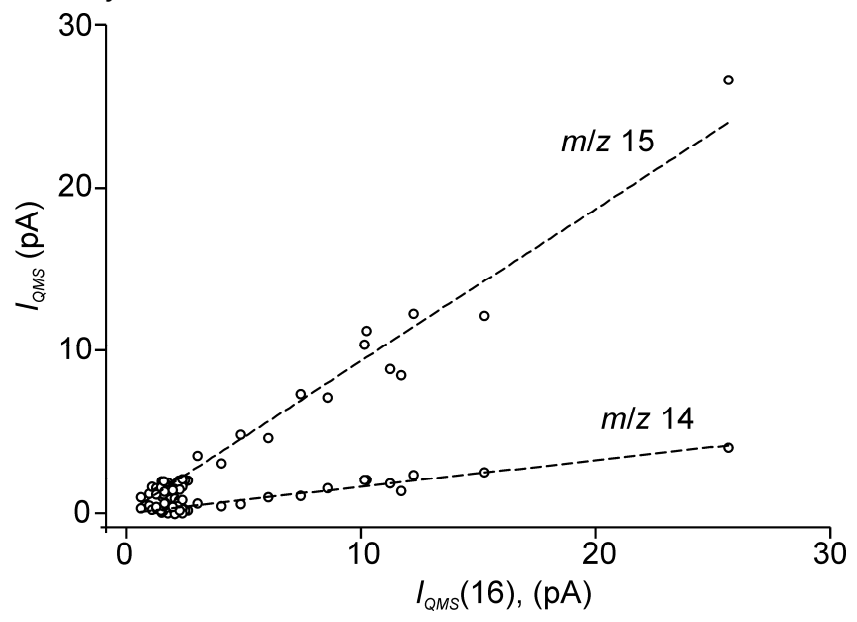

Figure 3. Representative pairwise linear regressions of mass-spectrometer signals: $\mathrm{m} / \mathrm{z} 14$ and $\mathrm{m} / \mathrm{z} 15$ vs. $m / z$ 16. (Sample D-052, normal load $2.1 \mathrm{~N}$ )

The channel at $m / z=44$ correspond to a mixture of $\mathrm{CO}_{2}{ }^{+}$and $\mathrm{C}_{3} \mathrm{H}_{8}{ }^{+}$. The fraction of $\mathrm{C}_{3} \mathrm{H}_{8}{ }^{+}$was minor as it follows from the high values of the $I_{Q M S}(m / z 44) / I_{Q M S}(m / z 43)$ ratio, which exceeded the standard ratio for pure propane two to nine fold. Therefore, as a rough and ready estimation, the contribution of the $\mathrm{C}_{3} \mathrm{H}_{8}{ }^{+}$in the channel $m / z=44$ can be neglected and it can be assigned entirely to $\mathrm{CO}_{2}{ }^{+}$. Then, the $\mathrm{O}^{+}$ion current can be determined from the ion current of $\mathrm{CO}_{2}{ }^{+}, I_{\mathrm{QMS}}(\mathrm{m} / z$ 44), and the relative abundance of $\mathrm{O}^{+}(\mathrm{m} / \mathrm{z}=16)$ in the standard mass spectrum of $\mathrm{CO}_{2}, A(16,9)$ (the first number stands for the $\mathrm{m} / \mathrm{z}$ and the second one is the gas component number in the matrix Table A1):

$$
I_{\mathrm{QMS}}\left(\mathrm{O}^{+}\right)=A(16,9) I_{\mathrm{QMS}}(m / z 44) \text {. }
$$

$\mathrm{CH}_{4}+$ ion current can now be found as:

$$
I_{\mathrm{Qms}}\left(\mathrm{CH}_{4}{ }^{+}\right)=I_{\mathrm{Qms}}\left(m / z \text { 16)-IQms }\left(\mathrm{O}^{+}\right)\right. \text {. }
$$

Linear regressions were newly fitted to the plots of $\operatorname{IQMS}_{\mathrm{Q}}\left(\mathrm{CH}_{3}{ }^{+}\right)$against the $I_{\mathrm{QMS}}\left(\mathrm{CH}_{4}\right)$, which was calculated using (2), for the three samples and four normal loads. Figure 4 (c) shows the slopes of these linear regressions. Most of the slopes are close to the standard ratio of $\mathrm{CH}_{3}{ }^{+}$and $\mathrm{CH}_{4}{ }^{+}$for 
methane except for D-050 at 0.84 and $1.24 \mathrm{~N}$, which were significantly smaller than the standard ratio. In these particular cases, the contribution from $\mathrm{O}^{+}$in $I_{Q M S}(\mathrm{~m} / \mathrm{z} 16)$ can be even larger, than we expected on the basis of our assumption, for example, because of additional $\mathrm{CO}$ emission. These findings underpin the hypothesis of dominating $\mathrm{CO}_{2}{ }^{+}$in the channel $m / z=44$.

A similar approach was used to analyse the origin for ions with $m / z=26-29$ (ethane group). Before fitting linear regressions to the data, the contribution from $\mathrm{CO}_{2}$ in the channel $\mathrm{m} / \mathrm{z} 28$ was subtracted:

$$
I_{\text {QMS }}^{*}(m / z 28)=I_{Q M S}(m / z 28)-A(28,9) I_{Q M S}(m / z 44),
$$

where $A(28,9)$ is the relative abundance of $\mathrm{CO}^{+}(\mathrm{m} / z=28)$ in the standard mass spectrum of $\mathrm{CO}_{2}$. The slopes of the linear regressions are shown in Figure 5. For all three samples and all normal loads, the measured ratios $I_{\mathrm{QMS}}(\mathrm{m} / \mathrm{z} 26) / I_{\mathrm{QMS}}^{*}(\mathrm{~m} / \mathrm{z} 28)$ and $I_{\mathrm{QMS}}(\mathrm{m} / \mathrm{z} 27) / I_{\mathrm{QMS}}^{*}(\mathrm{~m} / z$ 28) were significantly smaller than the corresponding standard ratios for ethane. Furthermore, for D-051 and D-052 the measured ratio $I_{\mathrm{QMS}}(\mathrm{m} / \mathrm{z} 29) / I_{\mathrm{QMS}}^{*}(\mathrm{~m} / \mathrm{z} 28)$ was nearly equal to or slightly higher than the standard one, but for D-050 it was notably smaller than the standard ratio. Thus, it was concluded that ethane did not solely fit the experimental data.
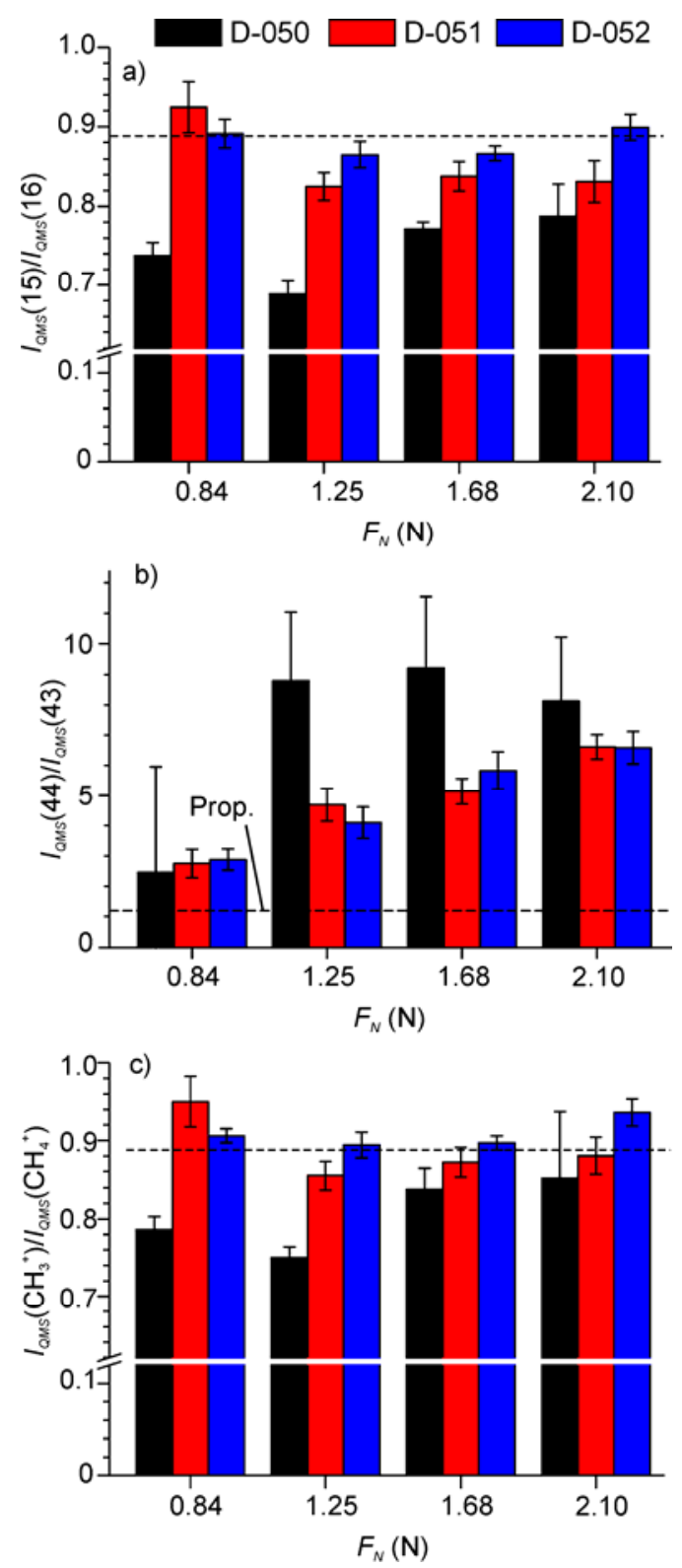
Figure 4. The ratios of various differential mass-spectrometer signals determined from the slopes of linear fits of experimental data: (a) $m / z 15$ vs. $m / z$ 16; (c) the ratio of the signals at $m / z 15\left(\mathrm{CH}_{3}{ }^{+}\right)$and the signal at $\mathrm{m} / \mathrm{z} 16\left(\mathrm{CH}_{4}{ }^{+}\right)$rectified from the component $\mathrm{O}^{+}$originated from $\mathrm{CO}_{2}$. The horizontal dashed lines show the standard ratios between the corresponding ion fragments for pure gases: (a) and (c) methane, (b) propane.

Another important observation has been a good correlation between the channels $m / z 28$ and $m / z 16$ (Figure 6 (a)) despite the fact that none of the possible emitted gases has both of these components strong in their corresponding standard mass-spectra. In fact, the slope of linear regression $I_{Q M S}(m / z 28)$ vs. IQMS $(m / z 16)$ was almost two orders of magnitude smaller than the ratio of the corresponding peaks in both $\mathrm{CO}$ and ethane standard mass-spectra. Although the mixture of ethane and $\mathrm{CO}$ could explain the excess of ions with $m / z 28$ observed for $I_{Q M S}(m / z 26) / I^{*} \mathrm{QMs}(\mathrm{m} / z$ 28) and $I_{Q M S}(m / z 27) / I_{Q M S}^{*}(m / z 28)$, it fails to explain the lack of excess of the same ions for $I_{Q M S}(m / z$ $29) / I^{*} \mathrm{QMS}(m / z 28)$. This points at the presence of some additional components among the emitted gases. Cyclopropane and propene have to be discarded because they would cause an opposite effect: an excess of ions with $m / z 26$ and $m / z$ 27. In turn, propane and, less likely, butane and/or iso-butane are the plausible candidates. The measured ratio $\operatorname{IQMS}(m / z 16) / \operatorname{IQMS}(m / z 28)$ shown in Figure 6 (b) is directly proportional to the methane concentration and inversely proportional to the sum of concentrations of ethane, propane, $\mathrm{CO}$ and other minor components in the emitted gases. There is a clear increasing trend of this ratio with decreasing Ar/methane in the precursor gases, while normal load had no significant effect on it.
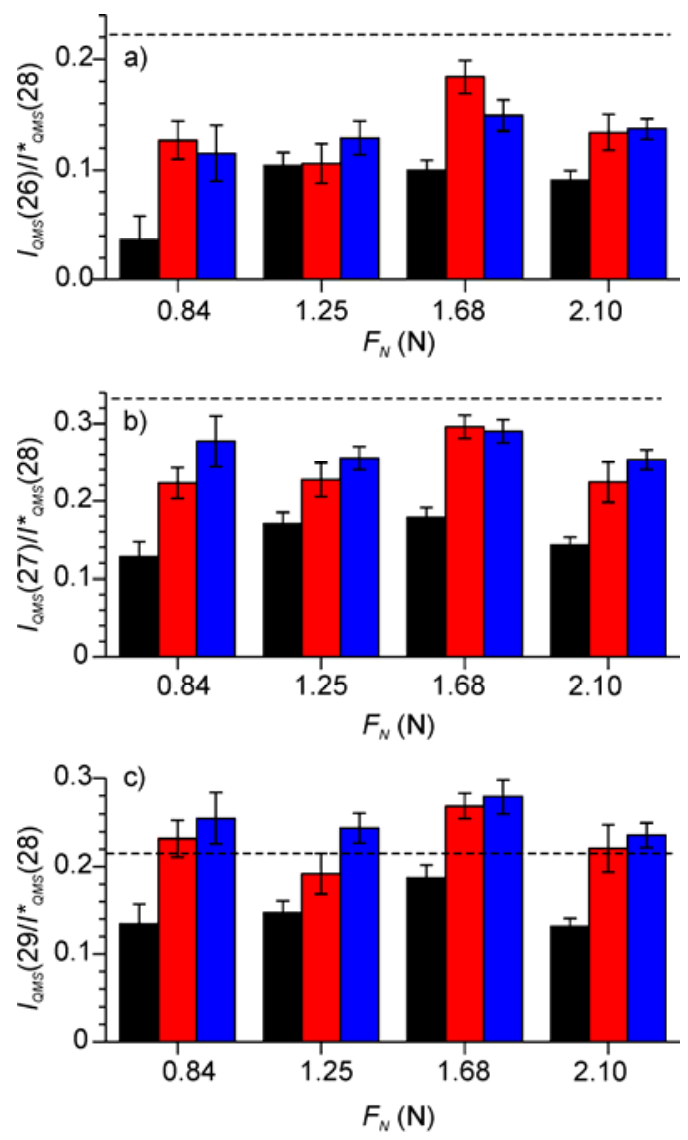

Figure 5. The ratios of various differential mass-spectrometer signals determined from the slopes of linear fits of experimental data: (a) $\mathrm{m} / \mathrm{z} 26$ vs. $\mathrm{m} / \mathrm{z} 28$; (b) $\mathrm{m} / \mathrm{z} 27$ vs. $\mathrm{m} / \mathrm{z} 28$; (c) $\mathrm{m} / \mathrm{z} 29 \mathrm{vs}$. $\mathrm{m} / \mathrm{z} 28$. The horizontal dashed lines show the standard ratios between the corresponding ion fragments for pure ethane. 

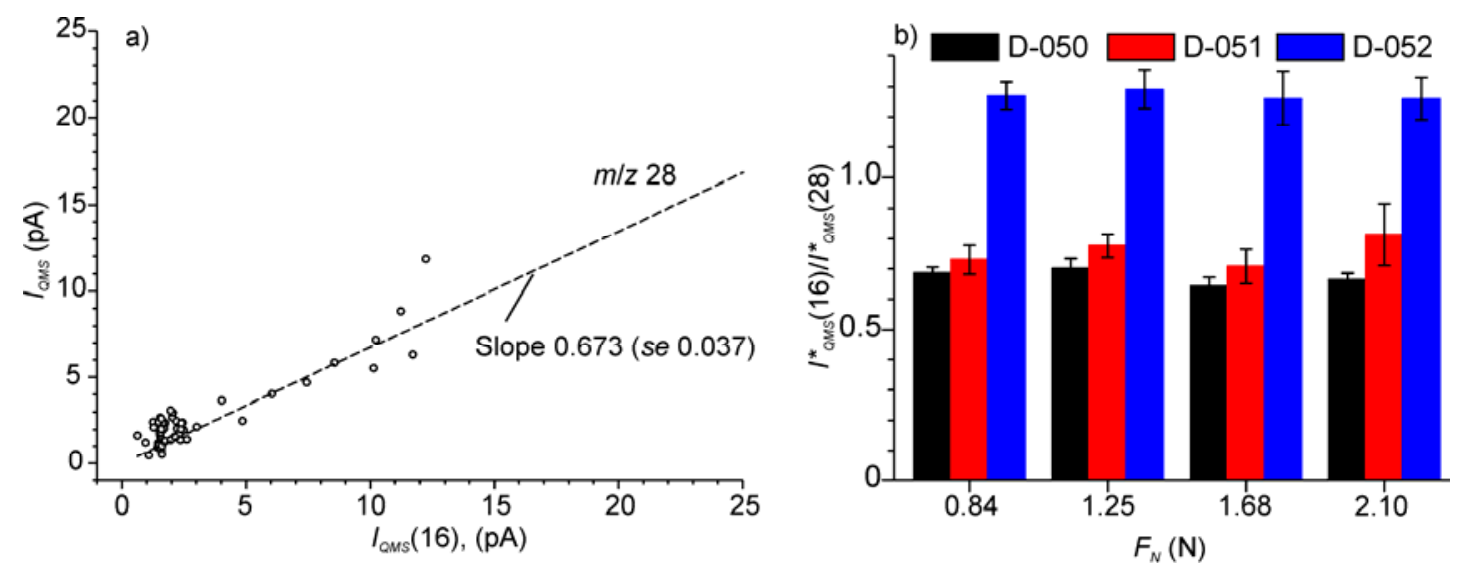

Figure 6. (a) The experimentally measured $I_{Q M S}(m / z 28)$ plotted against $I_{Q M S}(m / z ~ 16)$, from which the contribution of $\mathrm{CO} 2$ was removed. The dashed line shows linear regression fit. (b) The slopes of the linear regressions of $I_{Q M S}(m / z 16)$ vs. $(m / z 28)$ for different coatings and normal loads.

The analysis of the channels with $m / z$ 41-45 has generally supported the hypothesis relied on propane-butane gas emission (Figure 7). The propane-butane signals were notably less intensive and had larger dispersion than for methane and ethane-CO groups. The measured ratios $I_{Q M s}(\mathrm{~m} / z$ $41) / I_{\text {QMS }}(m / z 43)$ and $I_{Q M S}(m / z 42) / I_{\text {QMS }}(m / z 43)$ for D-051 and D-052 roughly matched the standard ratios for iso-butane and propane as shown in Figures 7 (a) and (b). For all coatings under normal load $0.84 \mathrm{~N}$ as well as for D-050 under all normal loads, the goodness of fit was low (the coefficient of determination between 0.2619 and 0.6305$)$. The high measured ratio $I_{Q M S}(m / z 45) / I_{Q M S}(m / z ~ 43)$ could not be ascribed to any possible alkane or alkene gas, but it can be associated with ethers and alcohols. Methoxymethane seems to be the most likely candidate since it has the main peaks at $\mathrm{m} / \mathrm{z} 15,29,45$ and 46 (Table A1). The coefficient of determination for $\mathrm{D}-050$ was between 0.3862 and 0.5010 , whereas for D-051 and D-052 the goodness of fit was unsatisfactory ( $R^{2}$ adj. between 0.1233 and 0.1668$)$. 

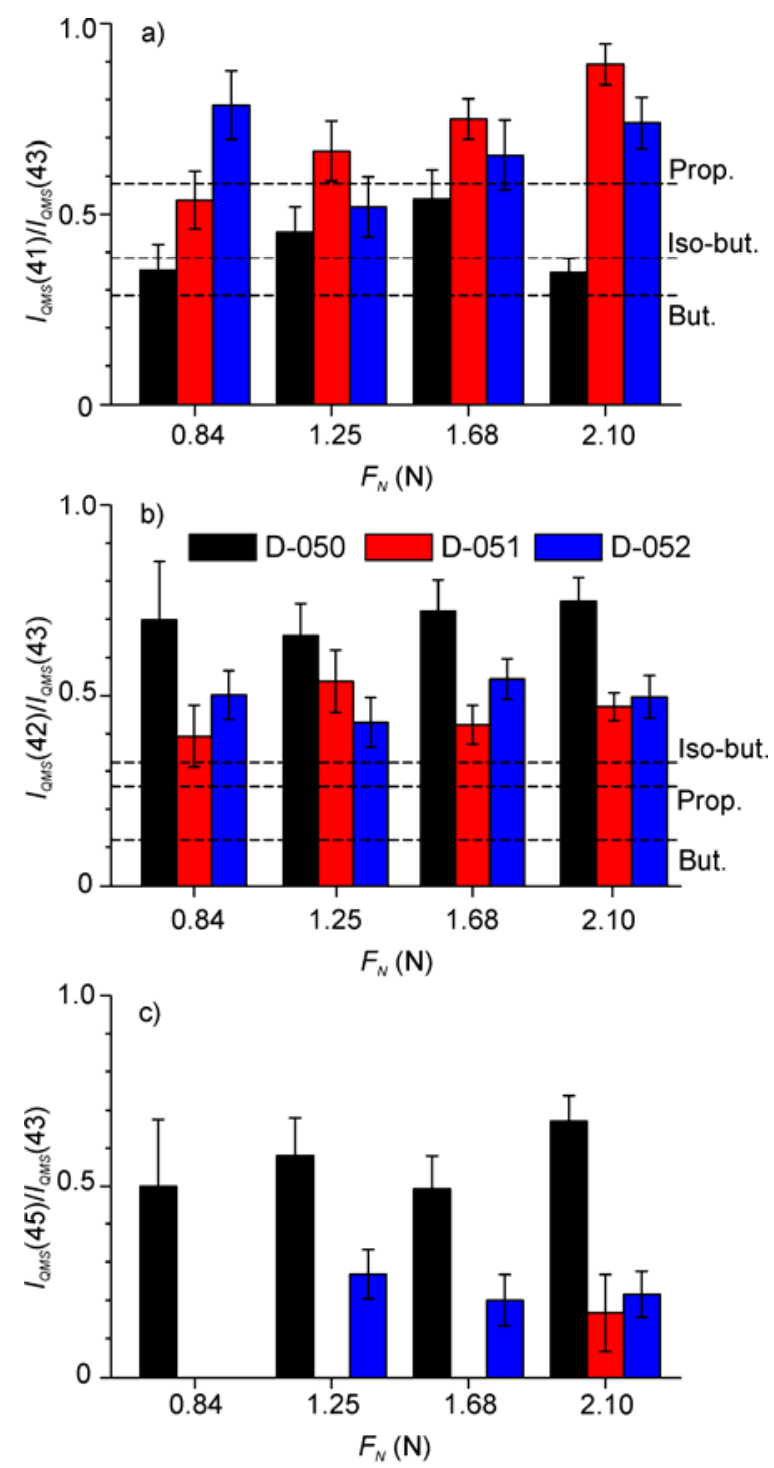

Figure 7. The ratios of various differential mass-spectrometer signals determined from the slopes of linear regression fits of experimental data: (a) $\mathrm{m} / \mathrm{z} 41$ to $\mathrm{m} / \mathrm{z} 43$; (b) $\mathrm{m} / \mathrm{z} 42$ to $\mathrm{m} / \mathrm{z} 43$; (c) $\mathrm{m} / \mathrm{z} 45$ to $\mathrm{m} / \mathrm{z}$ 43. The horizontal dashed lines show the standard ratios between the corresponding ion fragments for pure gases: prop. - propane, but. - butane, and iso-but. - iso-butane.

\subsubsection{Partial pressures of gas components}

The concentrations of the emitted gases or their partial pressures can be found from the system of linear equations considering that the measured mass-spectra are linear combinations of the standard mass-spectra of the emitted gases:

$$
M=A P,
$$

where $M$ is the vector of mean differential mass-spectrum, i.e. the averaged measured mass-spectrum with the background subtracted, $\Delta \bar{I}_{i}, A$ is the matrix of relative abundances of ions in the standard mass-spectra (Table A1) and $\boldsymbol{P}$ is the vector of partial pressures of the selected gases.

The $\Delta \bar{I}_{i}$ for the channels with $\mathrm{m} / \mathrm{z} 16,28$ and 43 were determined using integration of the corresponding mass-spectrometry time series, $I_{i}(\mathrm{t})$ :

$$
\Delta \bar{I}_{i}=\frac{1}{t_{1}-t_{0}} \int_{t_{0}}^{t_{1}}\left(I_{i}(t)-I_{i, b}\right) d t,
$$

where $i$ is the $m / z$ of the ions, $I_{i, b}$ is the steady background ion current before the beginning of rubbing, $t_{0}$ is the time of beginning of rubbing, $t_{1}$ is the time of the triboemission cessation after the rubbing 
end. The mean increase of the ion currents for methane, ethane and propane-butane groups of the measured mass-spectrometer channels was determined as a product of $\Delta \bar{I}_{m / z=16}, \Delta \bar{I}_{m / z=28}$ or $\Delta \bar{I}_{m / z=43}$ and the corresponding relative abundances.
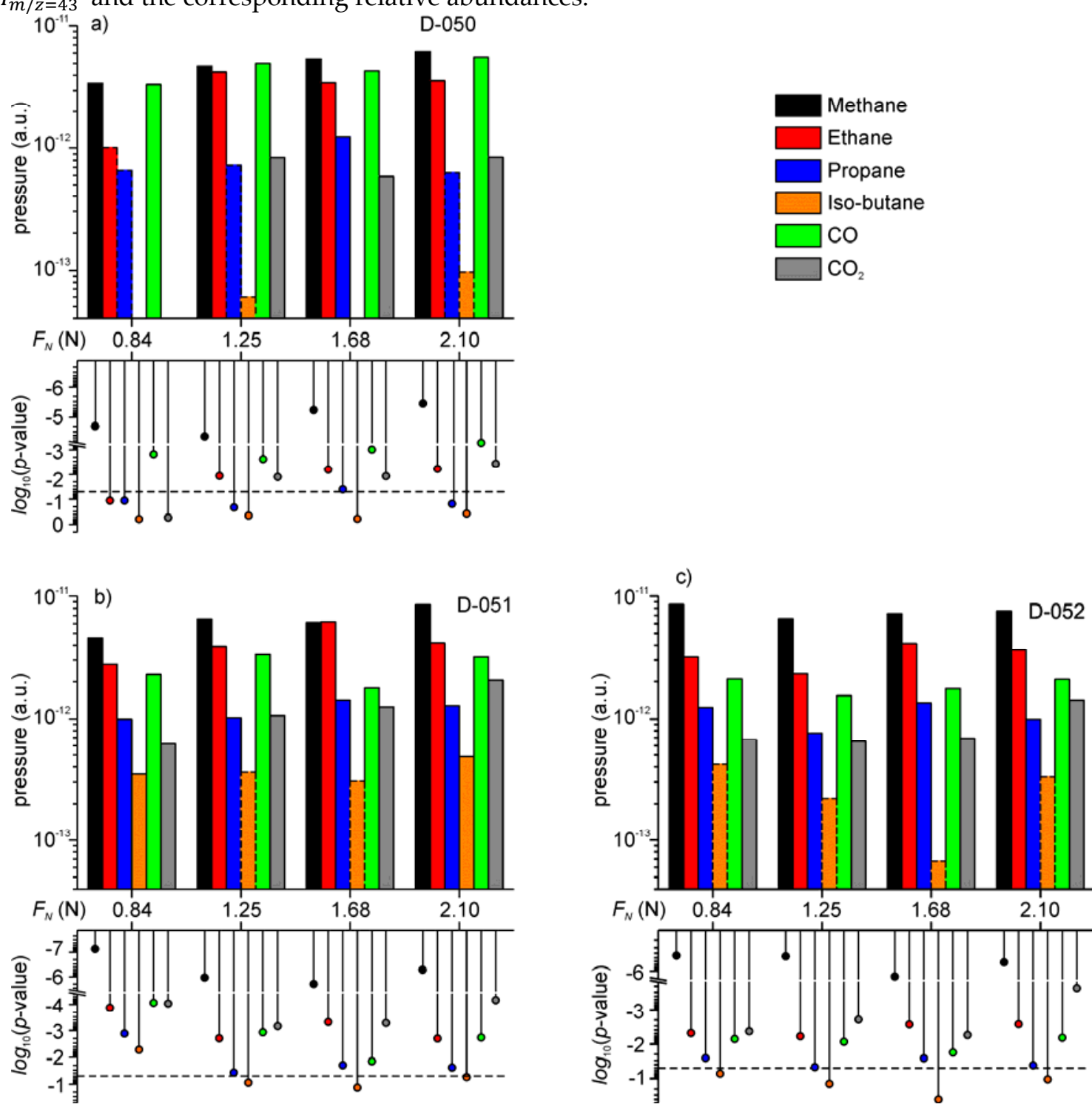

Figure 8. Partial pressures of six gases emitted under rubbing of a-C:H coatings under various normal loads: (a) D-050, (b) D-051, and (c) D-052. The corresponding $p$-values for each partial pressure are shown by the coloured dots below the bar graphs. The horizontal dashed lines mark the level of $p$ value 0.05 , which is accepted as an arbitrary threshold for statistical significance of results.

The channels at $m / z 20$ and 40, which correspond almost exclusively to Ar ions, and the channel at $m / z 2\left(\mathrm{H}_{2}+\right)$ were withdrawn from the measured mass-spectra before the analysis. The six gases: methane, ethane, propane, iso-butane, carbon mono- and dioxide, were selected on the base of the previous analysis to generate the matrix $A$. The partial pressures were found from the solution of (4):

$$
\boldsymbol{P}=\left(\boldsymbol{A}^{\mathrm{T}} \boldsymbol{A}\right)^{-1} \boldsymbol{A}^{\mathrm{T}} \boldsymbol{M},
$$

where superscript $\mathrm{T}$ stands for the transpose. The partial pressures were expressed in arbitrary units because of failing mass-spectrometer calibration for the specific gases. The standard error of $\boldsymbol{P}$, se $\boldsymbol{P}$, was calculated following the procedure described in [50]. For each element of $\boldsymbol{P}$ the following statistical significance testing was applied $-H_{0}:\left\|P_{\mathrm{i}}\right\|=0 ; H_{1}:\left\|P_{\mathrm{i}}\right\|>0$ ( $i$ is the number of the gas species). The partial pressures of the selected gases and the corresponding $p$-values are shown in Figure 8 for 
each coating and normal load. The horizontal dashed lines mark the level of $p$-value 0.05 , which is accepted as an arbitrary threshold for statistical significance of results.

The partial pressures of methane, ethane, $\mathrm{CO}$ and $\mathrm{CO}_{2}$ were statistically significant for all samples except for D-050 under the lowest load, where the emission was very weak. The propane triboemission was statistically significant only for D-051 and D-052. It should be stressed that this is the first time when propane and $\mathrm{CO}_{2}$ were resolved in the mixture. Also, this is the first time the triboemission of alkanes heavier than propane was found. The partial pressure of methoxymethane was very low (below $10^{-14}$ ) for D-050 and nil for the other two coatings.

Methane was the dominating emission component in all tests. The decrease of $\mathrm{Ar} / \mathrm{methane}$ ratio in the precursor gases led to the increase of the total triboemission rate that was accompanied by the compositional changes: the ratio of $\mathrm{CO}$ to methane decreased. Surprisingly, $\mathrm{CO}_{2}$ triboemission didn't follow the same trend as $\mathrm{CO}$, but remained nearly constant for the three coatings in all tests.

The emission rate was a weakly increasing function of the normal load. This was especially notable for D-050. Methane and ethane showed stronger dependence on the normal load, than the other gases.

\subsection{Tribological behaviour}

In a separate tribological test, all three samples demonstrated friction behaviour typical for aC:H coatings with corresponding hydrogen contents [8, 39, 51-53]. The coatings D-050 and D-051 with $\mathrm{H}$ content below 21 at.\% showed chaotic COF behaviour that oscillated between 0.2 and 0.9 . The highly hydrogenated a-C:H coatings such as D-052 usually exhibit transient decrease at the beginning of rubbing that in some cases results in superlow COF [8]. However, for D-052 superlow COF was not achieved. After reaching its minimum, the COF switched to a "solid" behaviour type (Figure 9 (a)). The higher the severity of loading, the shorter the duration of the initial transient decrease and the larger the minimal value of the COF. Similar behaviour of COF with varying sliding speed was reported recently by Liu et al. [54]. The coating damage due to rubbing was relatively small (Figure 9 (b)). In addition to fine powder-like debris concentrated on the sides of the wear tracks, partial coating spalling was observed inside the rubbed area. Spalling intensified with increasing the normal load (Figures 9 (c)-(e)).

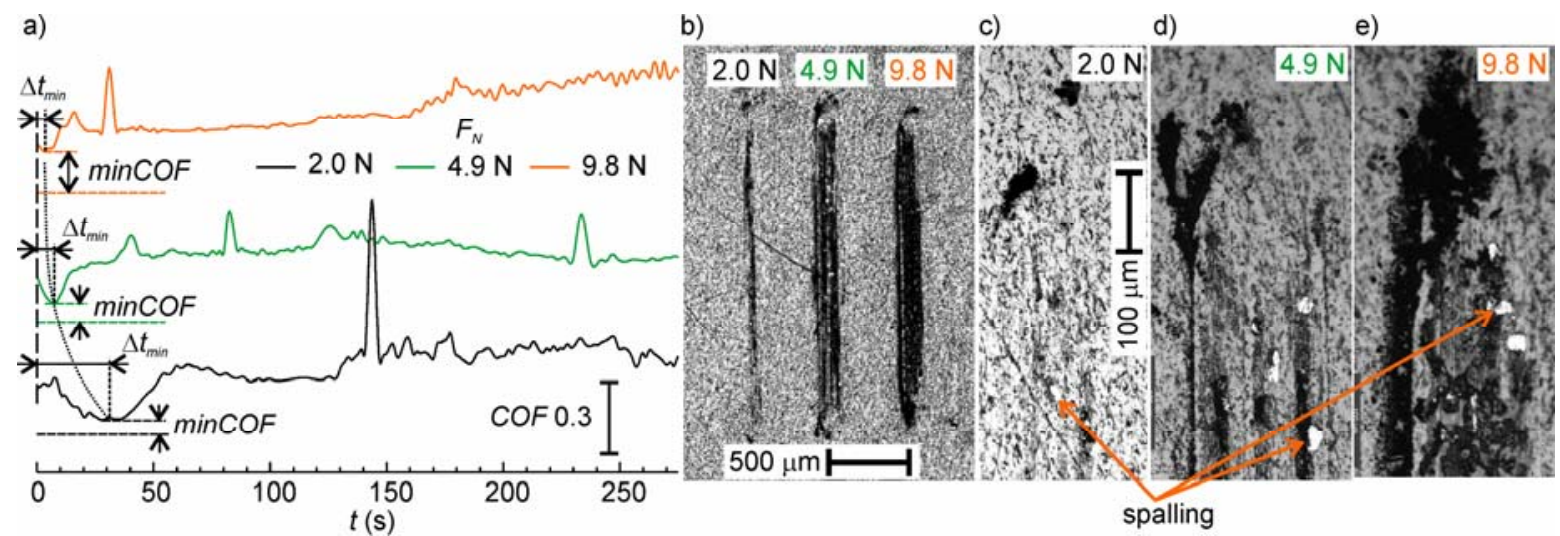

Figure 9. (a) Representative graphs of time series of coefficient of friction (COF) for D-052 in vacuum. (b)-(e) optical microscopy images of worn surfaces at various magnifications after tribological tests.

Similar damage was observed on the coatings surfaces after the gas triboemission tests (Figure 10), which were carried out at lower normal load, but with larger number of cycles, than in the tribological test. The least hydrogenated D-050 coating was completely worn through in the centre of the wear track, whereas the most hydrogenated D-052 one exhibited little powder-like debris. 


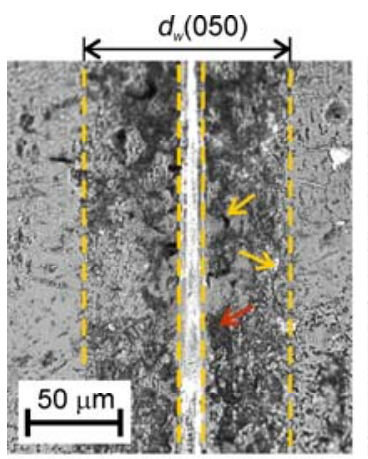

(a)

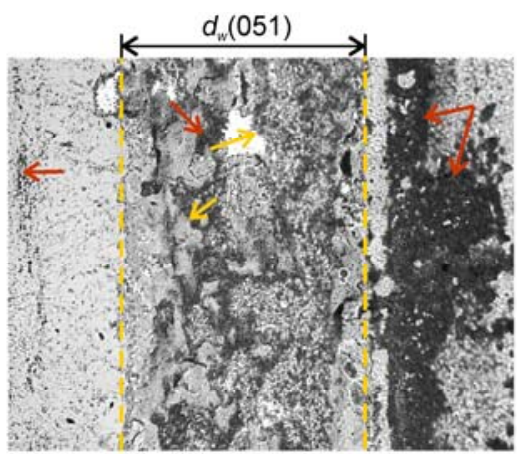

(b)

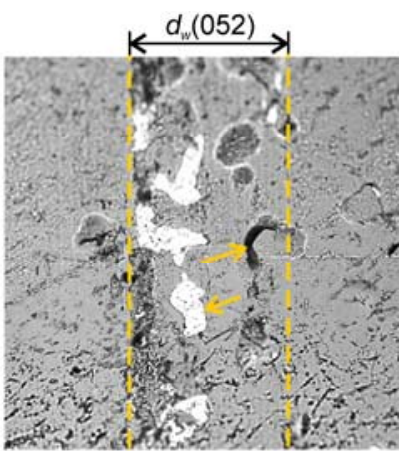

(c)

Figure 10. Optical microscopy images of the rubbed areas after gas triboemission tests. Red arrows show powder-like debris. Yellow arrows show spalling and the defects on the coatings.

\subsection{Physico-chemical characterization}

Figure 11 shows the chemical compositions of the coatings determined using ERDA and RBS. For the PECVD coatings, the chemical elements other than $\mathrm{H}$ and $\mathrm{C}$ were not observed. The coatings derived from pure methane (D-052) were uniform, with a monolayer structure and relatively high concentration of hydrogen. The coatings D-051 and D-052 derived from a gas discharge plasma that contained argon/methane mixtures had bilayer structure with nearly equal thickness of the top and the bottom layers. The $\mathrm{H}$ concentration in the top layer was significantly lower than in the bottom. Furthermore, the $\mathrm{H}$ concentrations in the bottom layers of both coatings were smaller than in D-052. The tendency to decrease the $\mathrm{H}$ content in the top layer with increasing Ar/methane proportion in the process gas was notable. This is in line with earlier studies in which the removal of hydrogen from the coating and its densification were reported when argon was added to the precursor gases $[2,55-57]$. The relative hydrogen depletion in the coatings is in a good agreement with the results of Capote et al. [58], although the absolute $\mathrm{H}$ concentration in a-C:H in our study was lower because of the use of methane instead of hexane as a precursor gas. The IBD coating D-2a also had a bilayer structure. The presence of oxygen and argon was notable in the bottom layer. Although the absolute $\mathrm{H}$ concentration in the bottom layer was lower than in the top layer, the $\mathrm{H} / \mathrm{C}$ ratio was nearly the same in both layers.

D-050

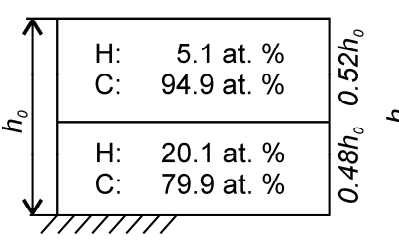

D-051

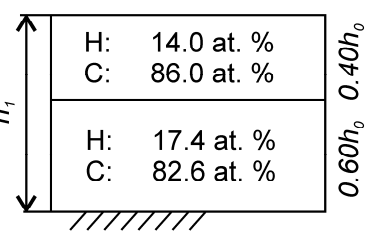

D-052

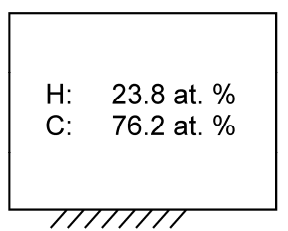

D-2a

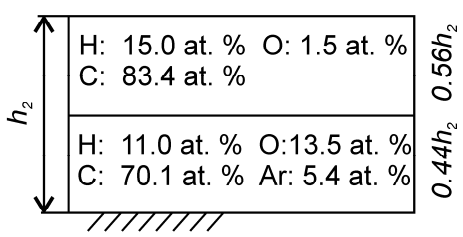

Figure 11. Schematic representation of the structure and composition of the PECVD (D-050, D-051 and D-052) and the IBD (D-2a) a-C:H coatings.

Figure 12 (a) shows the Raman spectra for the PECVD coatings with the overlapping bands known as D and G bands. The spectra were fitted using Gaussian functions. The position, the full width at half maximum (FWHM) and the intensity ratio of the D and G bands $\left(I_{D} / I_{G}\right)$ are shown in Fig. 12 (b). The increase of Ar/methane led to a blueshift of the G band and a redshift of the D band. These shifts were more pronounced than in the work of Capote et al. [58] who used Ar/hexane precursor gases. In addition, the band shifts were accompanied by the decrease in FWHM for both bands and the increase of $I_{D} / I_{G}$. This behaviour fully agrees with literature and is usually interpreted in terms of an increase of graphitic domains and removal of bond-angle disorder [58-62]. 
The results are consistent with previous works $[57,63]$ that show that, in hydrogenated a-C, virtually all $s p^{3}$ carbon atoms are bound to one or more hydrogen atoms rather than to other carbon atoms through four-fold carbon-to-carbon bonding (pure diamond phase).
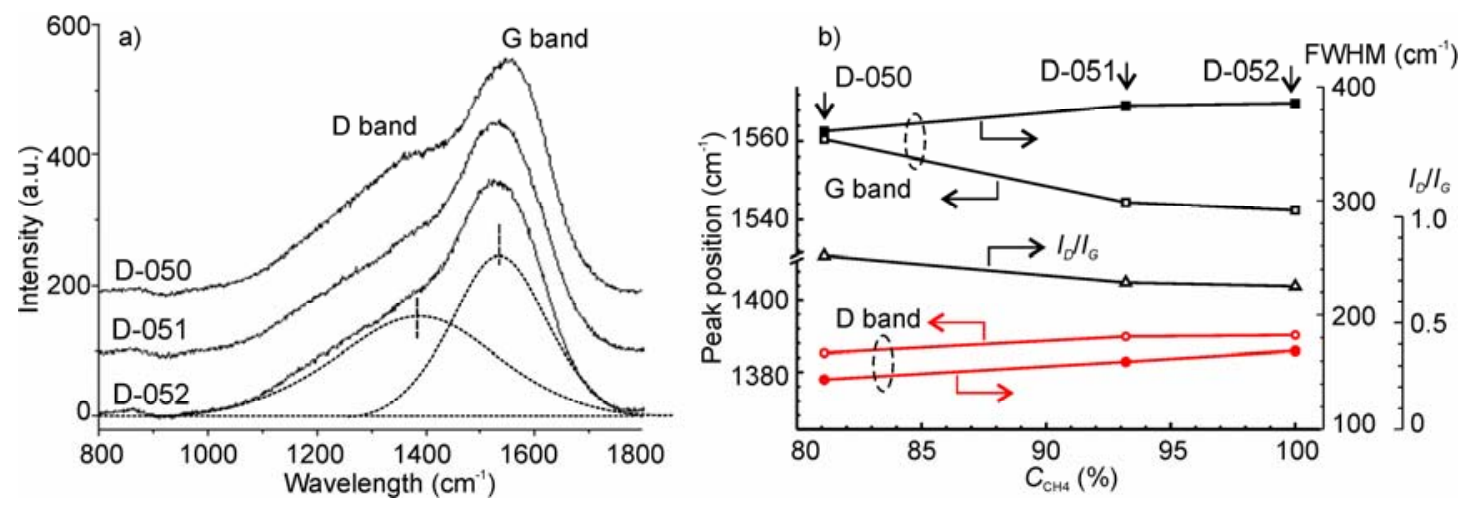

Figure 12. (a) The Raman spectra of the PECVD coatings. The dashed graphs show fitting of the D and G bands for D-052. (b) The results of data fitting: the band position, the FWHM of the bands and the ratio of the band intensities.

Figure 13 shows portions of ATR-FTIR spectra for the three coatings. The stretching and deformation bands of various $s p^{2}$ and $s p^{3} \mathrm{CH}_{x}$ groups didn't show any considerable difference between coatings and they were consistent with FTIR spectra of a-C:H coatings reported in literature $[40,64]$. The bands of symmetric and asymmetric stretching vibrations of $\mathrm{C}-\mathrm{O}$ were also found. Racine et al. [65] suggested that the intensity of $\mathrm{C}-\mathrm{O}$ bands is associated with the density of nanovoids in a$\mathrm{C}: \mathrm{H}$. This explains the correlation between the $\mathrm{C}-\mathrm{O}$ bands intensity and the Ar proportion in the precursor gases, since Ar bombardment leads to structural damage and increase of the real surface area. A weak and broad band at $3300 \mathrm{~cm}-1$ could be due to $\mathrm{OH}$ adsorption.
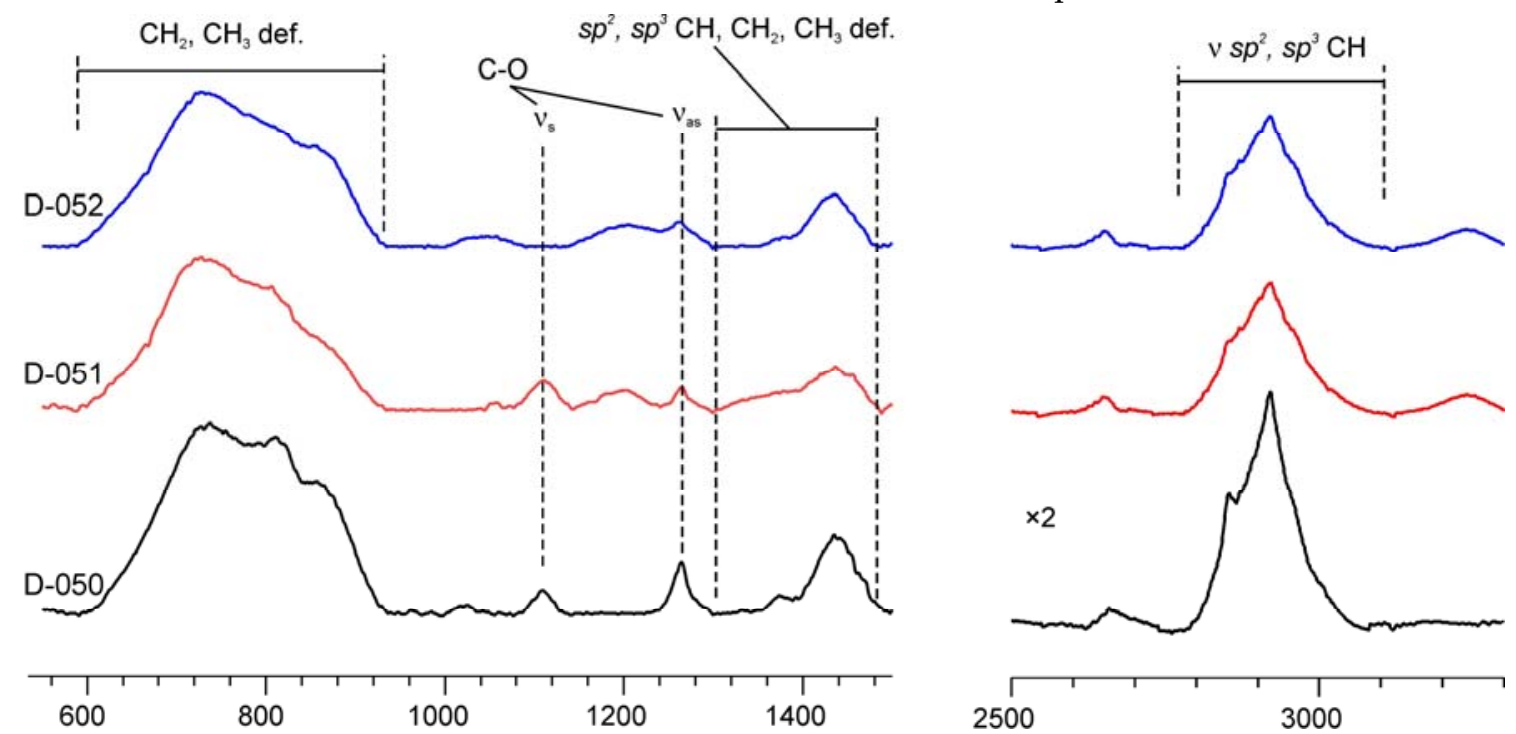

Figure 13. Portions of ATR-FTIR spectra for the three coatings.

\section{Discussion}

\subsection{Tribochemical origin of hydrocarbons and carbon oxides triboemission}

Numerous studies left no room for thermal desorption to explain triboemission under mild experimental conditions (sliding velocity and normal load), such as those in the present study [39, $40,42,54,66-70]$. It was shown that frictional heating is by far insufficient to excite highly energetic 
vibrational or electronic states or to produce C-C, C-O and C-H bond cleavage, which lay behind the observed triboemission of hydrocarbons and other gases. Tribochemistry postulates that the mechanical energy is converted into heat not directly but through excitation of different metastable states in mechanically distorted solid materials [71-73], while structural relaxation promotes a variety of chemical reactions and emission processes [72, 74]. Earlier it was suggested [40] that methane and ethane could be the products of first-order tribochemical reactions driven by the applied stress and shearing. These reactions have been supposed to consist in two steps: (I) formation of initial "activator" methyl or ethyl radical resulting from C-C bond cleavage, and (II) recombination of these radicals with hydrogen or methyl groups abstracted from a-C:H. The radicals are highly reactive and can initiate reactions with each other and with the network even at cryogenic temperatures [72]. The second step is energetically favoured due to hyperconjugative stabilization of hydrogenated amorphous carbon network. Intensive bond cleavage and formation under deformation were confirmed by quantum-chemical calculation and molecular dynamic simulations $[13,75,76]$.

The activation energy for cleavage of a chemical bond, $U(\sigma)$, is a decreasing function of the applied tensile stress, $\sigma$ [77]. Therefore, the rate of cleavage of thermally activated bonds significantly increases under applied stress:

$$
k=\tau_{0}^{-1} \exp \left(-\frac{U(\sigma)}{R T}\right),
$$

where $\tau_{0}$ is the oscillation period, $R$ is the gas constant and $T$ is the temperature. For complex structures like in a-C:H and polymers, $U$ is a non-linear function of $\sigma$ and depends on the localization of the strain, degree of cross-linking and chemical structure [72]. If the applied stress does not produce the bond cleavage, stress relaxation of the network may induce vibrational excitation. Shall at al. [13] concluded that phonon excitation is the principal mechanism of mechanical energy dissipation in a-C:H during sliding friction. Simultaneous action of tensile stress and vibrational excitation of carbon network may result in drastic reduction of the activation barrier for alkyl radical and atomic hydrogen formation from approximately $235 \mathrm{~kJ}^{\text {mole }} \mathrm{e}^{-1}$ to below $60 \mathrm{~kJ} \mathrm{~mole}^{-1}$ [78, 79]. Simulation showed that free radicals brought about due to bond cleavage of hydrogenated carbon network had typically 1 or 2 carbon atoms [71]. This agrees with our results which showed that $\mathrm{C} 1$ and C2 alkanes (methane and ethane) were the main emitted hydrocarbons.

Furthermore, higher cross-linking degree in a-C:H with low hydrogen content is expected to promote faster decay of excited states and lowering the probability of bond cleavage and triboemission intensity. In fact, the hydrocarbons emission rate decreased simultaneously with the decrease of hydrogen content in the coatings in the following order D-050<D-051<D-052. This is in line with literature (see Figure 1 in [40]). On the other hand, it can be expected that $\mathrm{H}_{2}$ triboemission can affect a-C:H mechanical properties, since extraction of dihydrogen should be accompanied by $s p^{3}$ to $s p^{2}$ transformation [10, 14, 16, 19, 75, 76, 80, 81], which was associated with densification of the modified surface layer of a-C:H $[82,83]$. Prospective experiments on atomic or nanometre scale can give insight into relationship between $\mathrm{H}_{2}$ triboemission and a-C:H mechanical properties.

This work has confirmed that tribochemical processes do not lead to triboemission of methyl radicals [39-41] that contrasts the results of thermal desorption from free surfaces [79, 84, 85]. This can be related with the confined geometry of sliding interface, which enhances the chances of freed radicals to recombine.

Triboemission of carbon monoxide clearly correlates with the intensity of C-O bands in ATRFTIR spectra. This suggests that $\mathrm{CO}$ emission can be associated with a reaction of $\mathrm{CO}$ detachment from the a-C:H surface by mechanical forces and vibrational excitation. The mechanisms of the possible methoxymetane emission are unclear yet and can be related with various reactions: detachment of $\mathrm{CO}$ radicals and their reaction with methyl radicals, conversion of surface hydroxyl into methoxy via substitution reaction with methyl radical followed by detachment of ether group, etc. [86]. Despite the diversity of tribochemical reactions laying behind triboemission of methane, ethane, propane and $\mathrm{CO}$, linear correlations between the time series of emission rates of these gases suggests similarity of the emission mechanisms, which can be tracked down to mechanical activation of bond cleavage and detachment of surface functional groups as well as to reaction between them. 


\subsection{Parallelilsm between gas triboemission and tribological behaviours}

\subsubsection{Triboemission of $\mathrm{H}_{2}$}

The observed complex hydrogen triboemission behaviour could be explained by the simultaneous emission from two sources: one at the coating and another at the substrate. In fact, microscopic analysis revealed that a portion of the steel surface was subjected to abrasion on the sites where the coating was worn through or peeled off (Figure 10). Previous studies showed that rubbing of iron and various steel grades usually leads to intensive $\mathrm{H}_{2}$ triboemission [87-91]. However, triboemission from AISI 420 steel grade has not been studied so far. To characterize $\mathrm{H}_{2}$ triboemission from a substrate a separate experiment was conducted.

a)

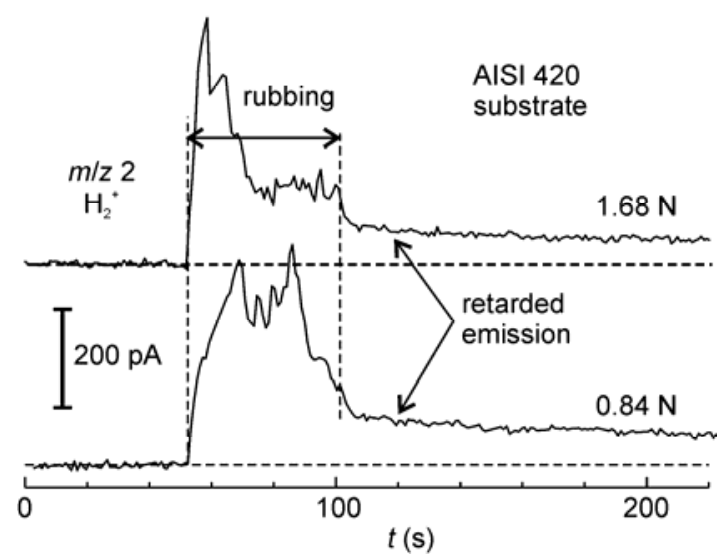

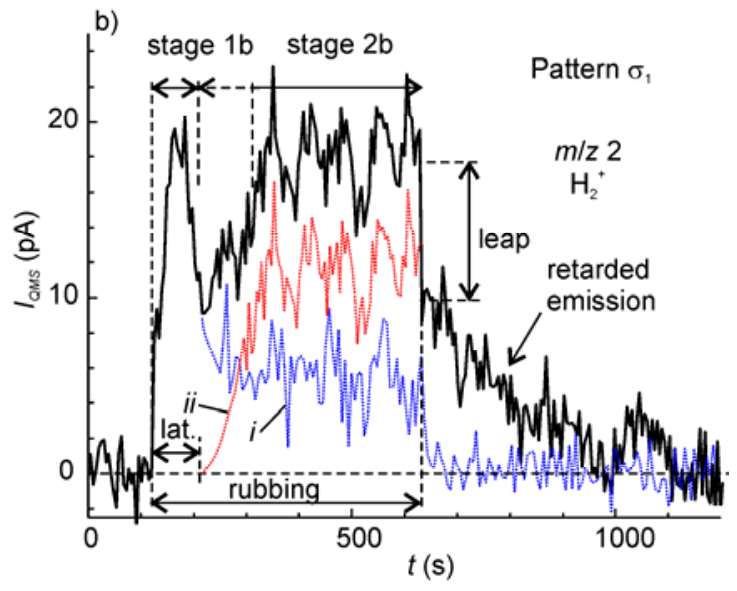

Figure 14. (a) Time series of a mass-spectrometry channel at $m / z 2\left(\mathrm{H}_{2}{ }^{+}\right)$in the experiment with rubbing a bare steel substrate. (b) Schematic decomposition of $\mathrm{H}_{2}{ }^{+}$time series in the triboemission test of D052. The blue dotted line (i) corresponds to $\mathrm{H}_{2}$ emission from the coating, the red one (ii) corresponds to $\mathrm{H}_{2}$ emission from the substrate.

Figure 14 (a) shows the $\mathrm{H}_{2}{ }^{+}$time series for bare steel, which have two distinct features in comparison with a-C:H-coated samples: the emission rate was almost an order of magnitude higher (note the vertical scale bar), and a retarded emission lasting for several hundreds of seconds after the rubbing end was observed. The retarded triboemission was previously reported for various metals and hydrides, where bulk diffusion is the rate limiting step [87, 89, 92]. $\mathrm{H}_{2}$ diffusion-desorption is driven by the concentration and stress gradients and depends on the disorder of the crystalline structure. Such behaviour is opposed to tribochemical processes of triboemission of $\mathrm{H}_{2}$ and $\mathrm{C}_{\mathrm{x}} \mathrm{H}_{\mathrm{y}}$ from a-C:H, which rely on short-lived (tens of picoseconds) vibrational excited states $[13,67,93,94]$ and other secondary processes of mechanical energy dissipation $[68,69,73,95,96]$. The absence of a leap at the end of rubbing means that $\mathrm{H}_{2}$ triboemission from the steel sample is entirely diffusiondesorption driven. In contrast, the time series of $\mathrm{H}_{2}$ triboemission from the coated sample (Figure 14 (b)) showed the presence of both the retarded emission and the leap that suggests that tribochemical and diffusion-desorption mechanisms co-existed. Schematically, the time series of $\mathrm{H}_{2}$ triboemission from a-C:H coating on a steel substrate can be modelled by a superposition of the two process denoted by blue and red dotted lines in Figure 14 (b). The initial peak (stage 1b) and a significant part of $\mathrm{H}_{2}$ triboemission on stage $2 \mathrm{~b}$ have to originate from a-C:H (i). The contribution from the substrate (ii) starts when the coating gets damaged and it gradually increased with the increase of degree of wear. The latency of $\mathrm{H}_{2}$ triboemission from the substrate is typical for iron and steel samples having a coating or an oxide layer on the surface [30,87].

\subsubsection{Triboemission of $\mathrm{Ar}$}

Triboemission of Ar (Figure 15) is worth of closer examination since it relates to neither tribochemical process, nor diffusion-desorption. The Ar atoms get trapped in the disordered a-C:H 
structure during the deposition process. At higher ion energies, Ar tends to localize at the bottom part of the coating [40]. The Ar atom is too big to effuse from the coating during storage or service life. However, when the coating gets damaged and new surfaces are created, almost all Ar atoms, which are situated close to the new surfaces, leave instantly (time constant 2.7-40 ps) because of very low adsorption energy (8.1-14.7 $\left.\mathrm{kJ} \mathrm{mole}^{-1}\right)$ and negligibly small equilibrium Ar surface coverage, $\theta_{\text {eq, }}$ at room temperature $\left(\theta_{e q}<10^{-10}\right)$.

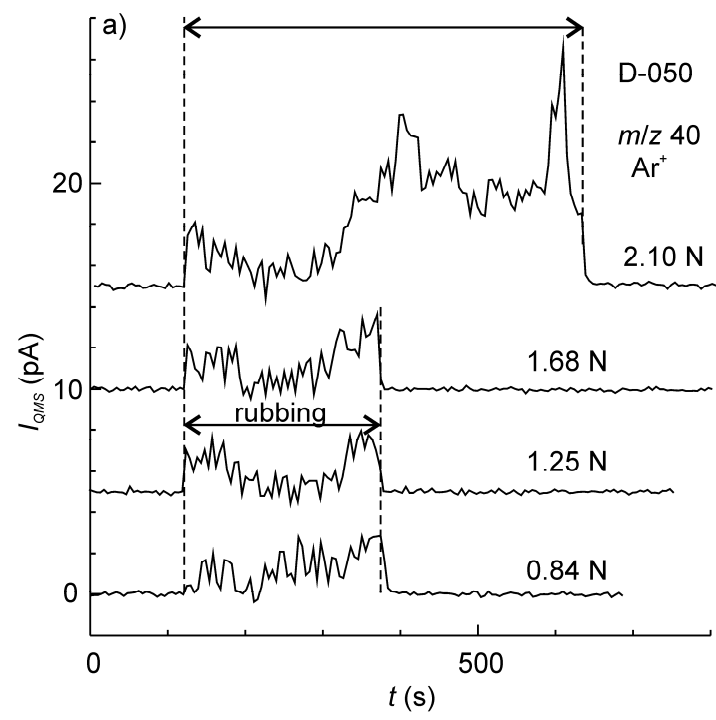

b)

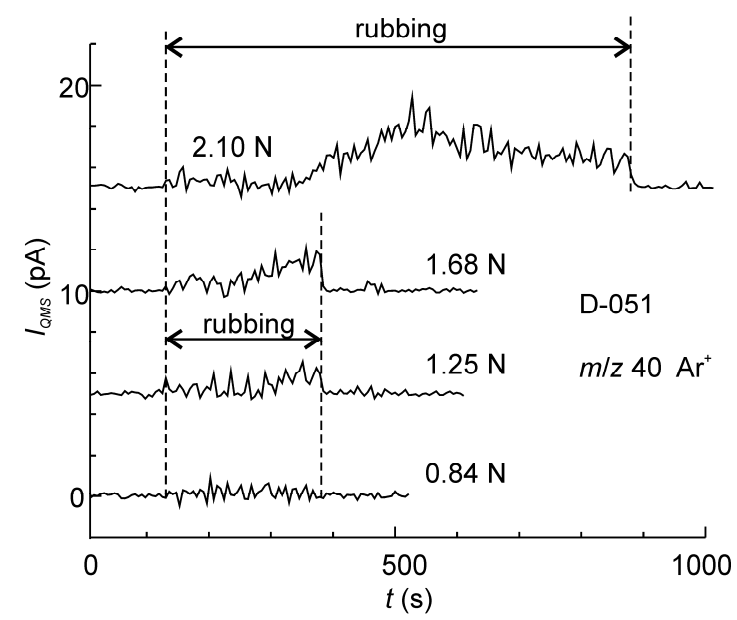

Figure 15. Time series of $\mathrm{Ar}^{+}$at various normal loads: (a) D-050, (b) D-051.

The rate of Ar emission is proportional to the surface coverage of Ar adatoms, $\theta(t)$, and the rate of new surface generation :

$$
Q(t)=\left(\theta(t)-\theta_{e q}\right) \frac{A(t+\Delta t)-A(t)}{\Delta t} n_{m}
$$

where $\Delta t$ is a small time interval, which is, however, considerably larger than the desorption time, $n_{m}$ is the surface density of adsorption sites and $A$ is the new surface area created since the beginning of sliding. Obviously, the $\theta(t)$ is directly proportional to local Ar concentration in the bulk, $C_{A r}(t)$, so (8) can be transformed:

$$
Q(t)=K R(t) C_{A r}(t),
$$

where $R(t) \approx \frac{d A(t)}{d t}$ is the rate of new surface generation and $K$ is the proportionality coefficient. This expression can shed light onto the complex behaviour of Ar triboemission and figure out how the degradation processes evolve in course of rubbing. For example, a sharp peak at the beginning of sliding of D-050 under all normal loads indicates that the coating was significantly damaged during run-in (Figure 15 (a)). In contrast, this did not happen to D-051 (Figure 15 (b)) suggesting smoother run-in. The decline of the triboemission rate at the end of the run-in stage can be due to slow down of the new surfaces generation $(R(t) \downarrow)$ and depletion of Ar in the plastically deformed surface layer $\left(C_{A r}(t) \downarrow\right)$. Upon the onset of severe wear the $R(t)$ increased and the Ar triboemission intensified again.

Expression (9) also explains the differences in Ar triboemission rates D-050 and D-051. Although RBS was not able to measure Ar concentrations in the coatings, which were below 1 at. \%, it is reasonable to assume that $\mathrm{Ar}$ concentration in the coating increases with $\mathrm{Ar} /$ methane ration in the precursor gases. In fact, mean Ar triboemission rate from D-050 was two- to three-fold higher than from D-051 (Figure 15).

It is worth mentioning that triboemission behaviour is correlated with wear but it is not with friction [39, 87]. Figure 16 a)-c) shows the results of a complementary test of a-C:H coating obtained using Ion Beam Deposition. The first stage can be confidently associated with run-in and normal wear of the coating without any significant damage. In this stage Ar triboemission gradually increased and stabilized with low rate, whereas coefficient of friction and $\mathrm{C}_{\mathrm{x}} \mathrm{H}_{\mathrm{y}}$ triboemission were high. A sudden 
damage happened to the coating at the beginning of the second stage as can be inferred from a sharp $\mathrm{Ar}^{+}$peak. The intensity of the peak indicates that large amount of new material was deformed or fractured, probably due to adhesion failure in the coating. After that, mean Ar triboemission continuously decreased with a series of sharp peaks and extinguished before the rubbing end. The behaviour of coefficient of friction was opposed: it dropped nearly two-fold at the beginning of the second stage and, then, it slowly increased with rubbing time. This can be explained by continuous grinding of debris in the contact zone, so that $C_{\mathrm{Ar}}$ was gradually depleting until it vanished completely. This result is endorsed by the optical microscopy images of the worn surface, which show complete removal of the coating on the wear track and a small amount of fine debris left on the uncovered substrate (Figure $16(\mathrm{~d})$ ).

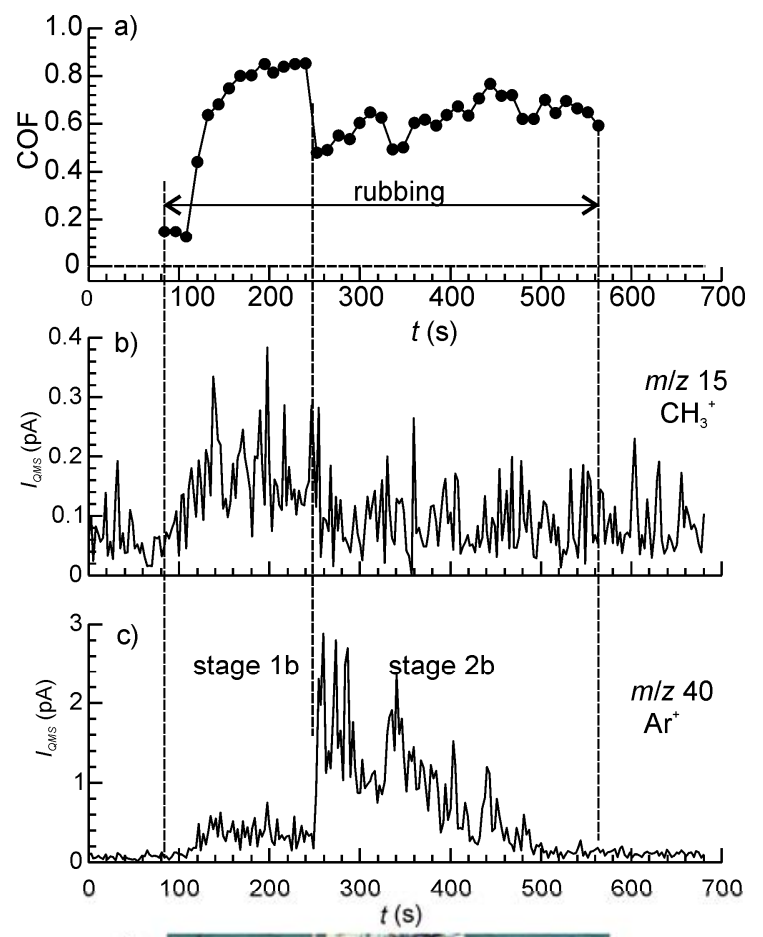

d)

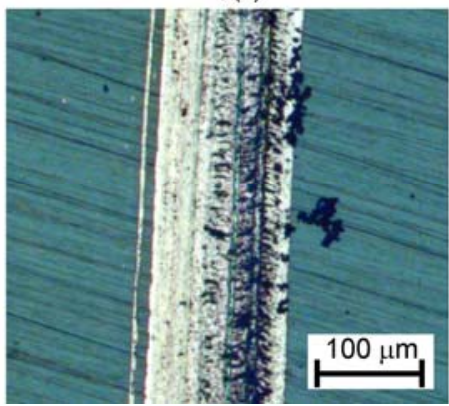

Figure 16. Results of a complementary experiment with the coating obtained by Ion Beam Deposition. The time series of: a) coefficient of friction (COF), b) the ions with $\mathrm{m} / \mathrm{z} 15\left(\mathrm{CH}_{3}^{+}\right)$c) the ions with $\mathrm{m} / \mathrm{z}$ $40\left(\mathrm{Ar}^{+}\right)$. d) Optical microscopy image of the worn surface.

\section{Conclusions}

Triboemission of gases was studied for a series of a-C:H coatings obtained by PECVD with various $\mathrm{Ar} /$ methane ratio in the precursor gases. The coatings had gradually varying chemical composition and structure that allowed us to correlate the triboemission behaviour with the coating properties and deposition conditions. The composition of the emitted gases was determined with higher accuracy than in previous works that was achieved by combination of three analytical methods: behavioural analysis, linear regression fitting and statistical hypothesis testing. For all three 
coatings, the emitted gases included C1-C3 alkanes, whose partial pressures decreased with increasing the number of carbon atoms in the molecule. For the coatings with higher hydrogen content, traces of higher alkanes, presumably iso-butane, were found for the first time. Triboemission of hydrocarbons was correlated with the chemical structure of the coatings: the triboemission rate increased with the increase of $\mathrm{H}$ and terminal methyl group concentrations. This finding backs up the tribochemical hypothesis.

All three coatings showed triboemission of carbon mono- and dioxide. The emission rates of these gases increased with the increase of $\mathrm{Ar} /$ methane ratio in the precursor gases. This was related to the defective nanopore coating structure, which was developed due to Ar bombardment and further was oxidized during storage in ambient air.

The coatings obtained with Ar admixture had a significant proportion of Ar in the triboemitted gases. Ar atoms got trapped in the a-C:H network at the deposition stage and released when the coating was deformed or fractured. The rate of Ar triboemission increased with the increase of $\mathrm{Ar} / \mathrm{methane}$ ratio in the precursor gases.

Hydrogen triboemission showed a complex triboemission behaviour, which was characterized by the presence of a leap at the end of rubbing and a retarded emission after the rubbing end. From the comparison of triboemission time series for the coated and bare substrates and microscopy analysis of worn surfaces, a superposition of two triboemission components was suggested. The components originated from two different sources - the coating and the substrate - had different emission mechanisms: for the coating the main mechanisms were tribochemical reactions and liberation of molecular $\mathrm{H}_{2}$ from the a-C:H network, whereas for the steel substrate $\mathrm{H}_{2}$ triboemission was a recombinative desorption of interstitial and trapped $\mathrm{H}$ (diffusion-desorption triboemission). The sources, mechanisms and behaviour patterns of triboemission of various gas species are summarized on Table 3.

Table 3. Correspondence between the behaviour patterns, triboemission sources and triboemission mechanisms for various gases

\begin{tabular}{|c|c|c|c|}
\hline Gas & Behaviour & Source & Mechanisms \\
\hline \multirow{2}{*}{$\mathrm{H}_{2}$} & \multirow{2}{*}{$\sigma_{1}$} & 1: Coating & $\begin{array}{l}\text { Tribochemical generation, } \\
\text { liberation of molecular } \mathrm{H}_{2}\end{array}$ \\
\hline & & 2: Substrate & $\begin{array}{l}\text { Diffusion - desorption of } \\
\text { interstitial and trapped } \mathrm{H}\end{array}$ \\
\hline $\mathrm{CH}_{4}, \mathrm{C}_{\mathrm{x}} \mathrm{H}_{\mathrm{y}}(\mathrm{x}>1)$ & \multirow[b]{2}{*}{$\mu$} & Coating & \multirow{2}{*}{ Tribochemical generation } \\
\hline $\mathrm{CO}, \mathrm{CO}_{2}, \mathrm{CH}_{3} \mathrm{OCH}_{3}(?)$ & & Coating (surface) & \\
\hline $\mathrm{Ar}$ & $\lambda$ & Coating (bulk) & Liberation of trapped Ar \\
\hline
\end{tabular}

A kinetic model of triboemission was applied for the analysis of time series in order to figure out the evolution of chemical and structural degradation in the coatings. Chemical degradation can be traced by the analysis of hydrocarbon and hydrogen triboemission that was associated to cleavage of chemical bonds and $s p^{3}$ to $s p^{2}$ transformation. Structural degradation, i.e. plastic deformation, fracture and so on, can be figured out via analysis of Ar time series.

Although in its actual configuration MSGE-MS system can only be used under vacuum, the obtained results have important implications for both vacuum and atmospheric applications of a$\mathrm{C}: \mathrm{H}$ coatings, since they give insight into basic tribochemical reactions.

\section{Acknowledgments}

The authors acknowledge M. Conte and A. Igartua for measuring coefficient of friction for the coatings in vacuum, S. Guerra for her help in experimental measurement of the mass-spectra, V. Elinson and A. Lyamin for kindly providing the IBD coatings, and J. Fontaine, J.-M. Martin and Th. Le Mogne for fruitful discussion and help in experimental measurement of the IBD coatings. This work was supported by the grant of The Ministry of Economy, Industry and Competitiveness of 
Spain (project Ref. BIA2016-79528-R). A.R. was financially supported by the Embassy of French Republic in Moscow and Ecole Central de Lyon in France. 


\section{Appendix A}

Table A1. Normalized standard mass-spectra of various C1-C4 hydrocarbons, $\mathrm{CO}$ and $\mathrm{CO}_{2}$ (adapted from NIST database [47]). The main components are highlighted in bold.

\begin{tabular}{|c|c|c|c|c|c|c|c|c|c|c|}
\hline$m / z$ & 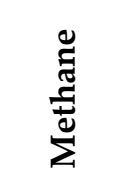 & 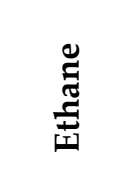 & 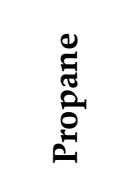 & 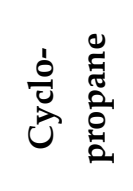 & 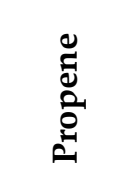 & 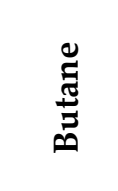 & 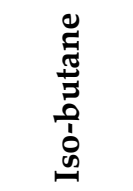 & O & రీ & 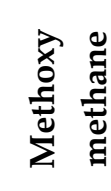 \\
\hline 12 & 0.0380 & 0.0040 & 0.0030 & 0.0100 & 0.0090 & 0.0010 & 0.0010 & 0.0470 & 0.0871 & 0.0020 \\
\hline 13 & 0.1069 & 0.0100 & 0.0060 & 0.0190 & 0.0140 & 0.0020 & 0.0020 & & & 0.0070 \\
\hline 14 & 0.2042 & 0.0300 & 0.0220 & 0.0601 & 0.0340 & 0.0080 & 0.0100 & & & 0.0220 \\
\hline 15 & 0.8879 & 0.0440 & 0.0721 & 0.0540 & 0.0550 & 0.0601 & 0.0681 & & & 0.2412 \\
\hline 16 & 1.0000 & 0.0010 & 0.0040 & 0.0020 & 0.0020 & 0.0010 & 0.0020 & 0.0170 & 0.0961 & 0.0110 \\
\hline 17 & 0.0164 & & & & & & & & & 0.0050 \\
\hline 19 & & & 0.0070 & 0.0230 & 0.0220 & & 0.0010 & & & 0.0010 \\
\hline 20 & & & 0.0080 & 0.0190 & 0.0180 & & 0.0010 & & & \\
\hline 22 & & & & & & & & & 0.0190 & \\
\hline 25 & & 0.0350 & 0.0050 & 0.0180 & 0.0180 & 0.0020 & 0.0010 & & & \\
\hline 26 & & 0.2322 & 0.0911 & 0.1271 & 0.1051 & 0.0581 & 0.0220 & & & \\
\hline 27 & & 0.3323 & 0.4194 & 0.3503 & 0.3873 & 0.3873 & 0.2783 & & & 0.0020 \\
\hline 28 & & 1.0000 & 0.5875 & 0.0250 & 0.0140 & 0.3213 & 0.0290 & 1.0000 & 0.0981 & 0.0100 \\
\hline 29 & & 0.2152 & 1.0000 & 0.0010 & & 0.4334 & 0.0621 & 0.0120 & 0.0010 & 0.3873 \\
\hline 30 & & 0.2622 & 0.0220 & & & 0.0100 & 0.0010 & & & 0.0100 \\
\hline 36 & & & 0.0030 & 0.0150 & 0.0180 & & 0.0010 & & & \\
\hline 37 & & & 0.0300 & 0.0991 & 0.1271 & 0.0070 & 0.0110 & & & \\
\hline 38 & & & 0.0530 & 0.1441 & 0.1942 & 0.0190 & 0.0260 & & & \\
\hline 39 & & & 0.1892 & 0.6726 & 0.7257 & 0.1361 & 0.1732 & & & \\
\hline 40 & & & 0.0280 & 0.3143 & 0.2913 & 0.0190 & 0.0270 & & & \\
\hline 41 & & & 0.1341 & 0.8878 & 1.0000 & 0.2853 & 0.3843 & & & 0.0010 \\
\hline 42 & & & 0.0601 & 1.0000 & 0.7036 & 0.1211 & 0.3233 & & & 0.0030 \\
\hline 43 & & & 0.2312 & 0.0330 & 0.0230 & 1.0000 & 1.0000 & & & 0.0140 \\
\hline 44 & & & 0.2742 & 0.0010 & 0.0010 & 0.0330 & 0.0330 & & 1.0000 & 0.0060 \\
\hline 45 & & & 0.0090 & & & 0.0010 & 0.0010 & & 0.0120 & 1.0000 \\
\hline 46 & & & & & & & & & 0.0040 & 0.6075 \\
\hline 49 & & & & & & 0.0020 & 0.0020 & & & \\
\hline 50 & & & & & & 0.0110 & 0.0080 & & & \\
\hline 51 & & & & & & 0.0100 & 0.0070 & & & \\
\hline 52 & & & & & & 0.0030 & 0.0020 & & & \\
\hline 53 & & & & & & 0.0090 & 0.0060 & & & \\
\hline 54 & & & & & & 0.0020 & 0.0010 & & & \\
\hline 55 & & & & & & 0.0100 & 0.0040 & & & \\
\hline 56 & & & & & & 0.0080 & 0.0310 & & & \\
\hline 57 & & & & & & 0.0250 & 0.0260 & & & \\
\hline 58 & & & & & & 0.1221 & 0.0010 & & & \\
\hline
\end{tabular}

\section{References}


[1] Wang L, Zhang R, Jansson U, Nedfors N. A near-wearless and extremely long lifetime amorphous carbon film under high vacuum. Scientific Reports. 2015;5:11119.

[2] Aijaz A, Louring S, Lundin D, Kubart T, Jensen J, Sarakinos K, et al. Synthesis of hydrogenated diamondlike carbon thin films using neon-acetylene based high power impulse magnetron sputtering discharges. Journal of Vacuum Science \& Technology A: Vacuum, Surfaces, and Films. 2016;34:061504.

[3] Gupta P, Becker HW, Williams GVM, Hübner R, Heinig KH, Markwitz A. Collision cascades enhanced hydrogen redistribution in cobalt implanted hydrogenated diamond-like carbon films. Nuclear Instruments and Methods in Physics Research Section B: Beam Interactions with Materials and Atoms. 2017;394:6-11.

[4] Donnet C, Grill A. Friction control of diamond-like carbon coatings. Surface and Coatings Technology. 1997;94-95:456-62.

[5] Ronkainen H, Koskinen J, Likonen J, Varjus S, Vihersalo J. Characterization of wear surfaces in dry sliding of steel and alumina on hydrogenated and hydrogen-free carbon films. Diamond and Related Materials. 1994;3:1329-36.

[6] Donnet C, Fontaine J, Grill A, Le Mogne T. The role of hydrogen on the friction mechanism of diamond-like carbon films. Tribology Letters. 2001;9:137-42.

[7] Gao F, Erdemir A, Tysoe W. The Tribological Properties of Low-friction Hydrogenated Diamond-like Carbon Measured in Ultrahigh Vacuum. Tribology Letters. 2005;20:221-7.

[8] Fontaine J, Le Mogne T, Loubet JL, Belin M. Achieving superlow friction with hydrogenated amorphous carbon: some key requirements. Thin Solid Films. 2005;482:99108.

[9] Park SJ, Lee K-R, Ko D-H. Tribochemical reaction of hydrogenated diamond-like carbon films: a clue to understand the environmental dependence. Tribology International. 2004;37:913-21.

[10] Erdemir A, Donnet C. Tribology of diamond-like carbon films: recent progress and future prospects. Journal of Physics D: Applied Physics. 2006;39:R311.

[11] Grill A. Review of the tribology of diamond-like carbon. Wear. 1993;168:143-53.

[12] Cui L, Zhou H, Zhang K, Lu Z, Wang X. Bias voltage dependence of superlubricity lifetime of hydrogenated amorphous carbon films in high vacuum. Tribology International. 2018;117:107-11.

[13] Schall JD, Gao G, Harrison JA. Effects of Adhesion and Transfer Film Formation on the Tribology of Self-Mated DLC Contacts. The Journal of Physical Chemistry C. 2010;114:5321-30.

[14] Merkle AP, Erdemir A, Eryilmaz OL, Johnson JA, Marks LD. In situ TEM studies of tribo-induced bonding modifications in near-frictionless carbon films. Carbon. 2010;48:58791.

[15] Liu Y, Erdemir A, Meletis EI. An investigation of the relationship between graphitization and frictional behavior of DLC coatings. Surface and Coatings Technology. 1996;86-87:564-8.

[16] Liu YAN, Meletis EI. Evidence of graphitization of diamond-like carbon films during sliding wear. Journal of Materials Science. 1997;32:3491-5. 
[17] He M, Lee S, Yeo C-D. Investigating atomic structure of thin carbon film under mechanical stress and frictional heat generation. Surface and Coatings Technology. 2015;261:79-85.

[18] Hayashi K, Tezuka K, Ozawa N, Shimazaki T, Adachi K, Kubo M. Tribochemical Reaction Dynamics Simulation of Hydrogen on a Diamond-like Carbon Surface Based on Tight-Binding Quantum Chemical Molecular Dynamics. The Journal of Physical Chemistry C. 2011;115:22981-6.

[19] Sánchez-López JC, Erdemir A, Donnet C, Rojas TC. Friction-induced structural transformations of diamondlike carbon coatings under various atmospheres. Surface and Coatings Technology. 2003;163-164:444-50.

[20] Wang L, Duan F. Nanoscale wear mechanisms of few-layer graphene sheets induced by interfacial adhesion. Tribology International. 2018;123:266-72.

[21] Erdemir A. The role of hydrogen in tribological properties of diamond-like carbon films. Surface and Coatings Technology. 2001;146-147:292-7.

[22] Fontaine J, Belin M, Le Mogne T, Grill A. How to restore superlow friction of DLC: the healing effect of hydrogen gas. Tribology International.37:869-77.

[23] Tireli M, Juribasic Kulcsar M, Cindro N, Gracin D, Biliskov N, Borovina M, et al. Mechanochemical reactions studied by in situ Raman spectroscopy: base catalysis in liquidassisted grinding. Chemical Communications. 2015;51:8058-61.

[24] Miyajima M, Kitamura K, Matsumoto K. Characterization of Tribofilm with the Remaining Lubricating Oil by Raman Spectroscopy. Tribology Online. 2015;10:225-31.

[25] Meylan B, Ciani D, Zhang B, Cuche E, Wasmer K. A new ball-on-disk vacuum tribometer with in situ measurement of the wear track by digital holographic microscopy. Surface Topography: Metrology and Properties. 2017;5:044004.

[26] Krick B, Vail J, Persson BJ, Sawyer WG. Optical In Situ Micro Tribometer for Analysis of Real Contact Area for Contact Mechanics, Adhesion, and Sliding Experiments. Tribology Letters. 2012;45:185-94.

[27] Nanao H, Hoshi Y, Takiwatari K, Mori S. In Situ Observation of Grease Lubrication Film under Shearing Conditions by Micro Infrared Spectroscopy. Journal of japanese society of tribologists. 2017;62:296-9.

[28] Nevchoupa RA, De Segovia JL, Deulin EA. An UHV system to study gassing and outgassing of metals under friction. Vacuum. 1999;52:73-81.

[29] Nevshupa RA, Conte M, Igartua A, Roman E, de Segovia JL. Ultrahigh vacuum system for advanced tribology studies: Design principles and applications. Tribology International. 2015;86:28-35.

[30] Nevshupa R, Grinkevich KE, Martinez I, Roman E. TriDes - a New Tool for the Design, Development and Non-Destructive Evaluation of Advanced Construction Steels. Materiales de Construcción. 2016;66:e099.

[31] Wu X, Cong P, Nanao H, Kobayashi K, Mori S. Chemisorption and Tribochemical Reaction Mechanisms of HFC-134a on Nascent Ceramic Surfaces. Langmuir. 2002;18:10122-7.

[32] Mori S, Kawada T, Xu WC. Tribochemical decomposition of formic acid on the nascent surfaces of steel formed by scratching. Applied Surface Science. 1997;108:391-7. 
[33] Gouider M, Berthier Y, Jacquemard P, Rousseau B, Bonnamy S, Estrade-Szwarckopf $\mathrm{H}$. Mass spectrometry during $\mathrm{C} / \mathrm{C}$ composite friction: carbon oxidation associated with high friction coefficient and high wear rate. Wear. 2004;256:1082-7.

[34] Řepa P, Rott M. Outgassing of metals stimulated by friction. Vacuum. 1997;48:775-8. [35] Wilkens W, Kranz O. The formation of gases due to the sliding friction of teflon on steel in ultrahigh vacuum. Wear. 1970;15:215-27.

[36] Ishikawa Y, Yoshimura T. Mechanically stimulated outgassing from stainless steel surface. Journal of Vacuum Science \& Technology A: Vacuum, Surfaces, and Films. 1991;9:2021-4.

[37] Miyoshi K. Aerospace mechanisms and tribology technology: Case study. Tribology International. 1999;32:673-85.

[38] Roberts EW. Space tribology: its role in spacecraft mechanisms. Journal of Physics D: Applied Physics. 2012;45:503001.

[39] Rusanov A, Nevshupa R, Fontaine J, Martin J-M, Le Mogne T, Elinson V, et al. Probing the tribochemical degradation of hydrogenated amorphous carbon using mechanically stimulated gas emission spectroscopy. Carbon. 2015;81:788-99.

[40] Rusanov A, Nevshupa R, Martin J-M, Garrido MÁ, Roman E. Tribochemistry of hydrogenated amorphous carbon through analysis of Mechanically Stimulated Gas Emission. Diamond and Related Materials. 2015;55:32-40.

[41] Igartua A, Berriozabal E, Nevshupa R, Roman E, Pagano F, Pleth Nielsen L, et al. Screening of diamond-like carbon coatings in search of a prospective solid lubricant suitable for both atmosphere and high vacuum applications. Tribology International. 2017;114:192200.

[42] Paulmier D, Zaidi H, Nery H, Huu TL, Mathia T. Tribological behaviour of diamondlike coatings: effect of active gases in atomic and molecular states. Surface and Coatings Technology. 1993;62:570-6.

[43] Sha Z-D, Sorkin V, Branicio PS, Pei Q-X, Zhang Y-W, Srolovitz DJ. Large-scale molecular dynamics simulations of wear in diamond-like carbon at the nanoscale. Applied Physics Letters. 2013;103:073118.

[44] Mahrova M, Conte M, Roman E, Nevshupa R. Critical insight into mechanochemical and thermal degradation of imidazolium-based ionic liquids with alkyl and monomethoxypoly(ethylene glycol) side chains. Journal of Physical Chemistry C. 2014;118:22544-52.

[45] Mayer M. Improved physics in SIMNRA 7. Nuclear Instruments and Methods in Physics Research Section B: Beam Interactions with Materials and Atoms. 2014;332:176-80.

[46] Nevshupa R, Conte M, del Campo A, Roman E. Analysis of tribochemical decomposition of two imidazolium ionic liquids on Ti-6Al-4V through Mechanically Stimulated Gas Emission Spectrometry. Tribology International. 2016;102:19-27.

[47] Stein (director) SE. "Mass Spectra" by NIST Mass Spec Data Center. In: Linstrom PJ, Mallard WG, editors. NIST Chemistry WebBook, NIST Standard Reference Database Number 69. Gaithersburg MD: National Institute of Standards and Technology; 2017.

[48] Yamauchi Y, Hino T, Ohzeki K, Kubota Y, Deyama S. Gas desorption behavior of graphite anodes used for lithium ion secondary batteries. Carbon. 2005;43:1334-6. 
[49] Matsumoto S, Setaka N. Thermal desorption spectra of hydrogenated and water treated diamond powders. Carbon. 1979;17:485-9.

[50] Nevshupa R, Martinez L, Alvarez L, Lopez MF, Huttel Y, Mendez J, et al. Influence of Thermal Ageing on Surface Degradation of Ethylene-Propylene-Diene Elastomer. Journal of Applied Polymer Science. 2011;119:242-51.

[51] Andersson J, Erck RA, Erdemir A. Friction of diamond-like carbon films in different atmospheres. Wear. 2003;254:1070-5.

[52] Meunier C, Alers P, Marot L, Stauffer J, Randall N, Mikhailov S. Friction properties of ta-C and a-C:H coatings under high vacuum. Surface and Coatings Technology. 2005;200:1976-81.

[53] Zhang W, Tanaka A, Wazumi K, Koga Y. Effect of environment on friction and wear properties of diamond-like carbon film. Thin Solid Films. 2002;413:104-9.

[54] Liu Y, Yu B, Cao Z, Shi P, Zhou N, Zhang B, et al. Probing superlubricity stability of hydrogenated diamond-like carbon film by varying sliding velocity. Applied Surface Science. 2018;439:976-82.

[55] Weissmantel C, Breuer K, Winde B. Hard films of unusual microstructure. Thin Solid Films. 1983;100:383-9.

[56] Zhang W, Tanaka A, Xu BS, Koga Y. Study on the diamond-like carbon multilayer films for tribological application. Diamond and Related Materials. 2005;14:1361-7.

[57] Grill A, Patel V. Effects of bias and inert gas on properties of diamond-like carbon deposited by d.c. PACVD. Diamond and Related Materials. 1994;4:62-8.

[58] Capote G, Silva GF, Trava-Airoldi VJ. Effect of hexane precursor diluted with argon on the adherent diamond-like properties of carbon films on steel surfaces. Thin Solid Films. 2015;589:286-91.

[59] Dillon RO, Woollam JA, Katkanant V. Use of Raman scattering to investigate disorder and crystallite formation in as-deposited and annealed carbon films. Physical Review B. 1984;29:3482-9.

[60] Peng XL, Clyne TW. Mechanical stability of DLC films on metallic substrates: Part I-Film structure and residual stress levels. Thin Solid Films. 1998;312:207-18.

[61] Trava-Airoldi VJ, Bonetti LF, Capote G, Santos LV, Corat EJ. A comparison of DLC film properties obtained by r.f. PACVD, IBAD, and enhanced pulsed-DC PACVD. Surface and Coatings Technology. 2007;202:549-54.

[62] Jokari-Sheshdeh M, Mahboubi F, Dehghani K. Structure and tribological behavior of diamond-like carbon coatings deposited on the martensitic stainless steel: The influence of gas composition and temperature. Diamond and Related Materials. 2018;81:77-88.

[63] Kim BK, Grotjohn TA. Comparison of a-C:H films deposited from methane-argon and acetylene-argon mixtures by electron cyclotron resonance-chemical vapor deposition discharges. Diamond and Related Materials. 2000;9:37-47.

[64] Buijnsters JG, Gago R, Jimenez I, Camero M, Agullo-Rueda F, Gomez-Aleixandre C. Hydrogen quantification in hydrogenated amorphous carbon films by infrared, Raman, and X-ray absorption near edge spectroscopies. J Appl Phys. 2009;105:093510-7. 
[65] Racine B, Benlahsen M, Zellama K, Zarrabian M, Villain JP, Turban G, et al. Hydrogen stability in diamond-like carbon films during wear tests. Applied Physics Letters. 1999;75:3479-81.

[66] Nakayama K, Yagasaki F. The Temperature of Triboplasma. Tribology Letters. 2017;66:10.

[67] Ribas-Arino J, Marx D. Covalent Mechanochemistry: Theoretical Concepts and Computational Tools with Applications to Molecular Nanomechanics. Chemical Reviews. 2012;112:5412-87.

[68] Nevshupa R. The role of athermal mechanisms in the activation of tribodesorption and triboluminisence in miniature and lightly loaded friction units. Journal of Friction and Wear. 2009;30:118-26.

[69] Nevshupa RA, Roman E, de Segovia JL. Model of the effect of local frictional heating on the tribodesorbed gases from metals in ultra-high vacuum. International Journal of Materials and Product Technology. 2010;38:57-65.

[70] Lan H, Kato T, Liu C. Molecular dynamics simulations of atomic-scale tribology between amorphous DLC and Si-DLC films. Tribology International. 2011;44:1329-32.

[71] Butyagin PY. Kinetics and Nature of Mechanochemical Reactions. Russian Chemical Reviews. 1971;40:901-15.

[72] Butyagin PY. Structural Disorder and Mechanochemical Reactions in Solids. Russian Chemical Reviews. 1984;53:1025-38.

[73] Heinicke G. Tribochemistry. Munchen: Carl Hanser Verlag; 1984.

[74] Nevshupa RA. Triboemission: an attempt of generalized classification. In: Kajdas C, editor. Tribology: Science and Applications. Vienna: PAS; 2004. p. 11-25.

[75] Ma T-B, Hu Y-Z, Wang H. Molecular dynamics simulation of shear-induced graphitization of amorphous carbon films. Carbon. 2009;47:1953-7.

[76] Gao GT, Mikulski PT, Chateauneuf GM, Harrison JA. The Effects of Film Structure and Surface Hydrogen on the Properties of Amorphous Carbon Films. The Journal of Physical Chemistry B. 2003; 107:11082-90.

[77] Cottrell AH. The time laws of creep. Journal of the Mechanics and Physics of Solids. 1952;1:53-63.

[78] Jiang X, Beyer W, Reichelt K. Gas evolution from hydrogenated amorphous carbon films. J Appl Phys. 1990;68:1378-80.

[79] Schenk A, Winter B, Biener J, Lutterloh C, Schubert UA, Kuppers J. Growth and thermal decomposition of ultrathin ion-beam deposited $\mathrm{C}: \mathrm{H}$ films. J Appl Phys. 1995;77:2462-73.

[80] Johnson JA, Woodford JB, Erdemir A, Fenske GR. Near-surface characterization of amorphous carbon films by neutron reflectivity. Applied Physics Letters. 2003;83:452-4.

[81] Eryilmaz OL, Erdemir A. On the hydrogen lubrication mechanism(s) of DLC films: An imaging TOF-SIMS study. Surface and Coatings Technology. 2008;203:750-5.

[82] Manimunda P, Al-Azizi A, Kim SH, Chromik RR. Shear-Induced Structural Changes and Origin of Ultralow Friction of Hydrogenated Diamond-like Carbon (DLC) in Dry Environment. ACS Applied Materials \& Interfaces. 2017;9:16704-14. 
[83] Fukumasu NK, Bernardes CF, Ramirez MA, Trava-Airoldi VJ, Souza RM, Machado IF. Local transformation of amorphous hydrogenated carbon coating induced by high contact pressure. Tribology International. 2018;124:200-8.

[84] Malhotra M, Kumar S. Thermal gas effusion from diamond-like carbon films. Diamond and Related Materials. 1997;6:1830-5.

[85] Biener J, Schenk A, Winter B, Lutterloh C, Schubert UA, Küppers J. Hydrogenation of amorphous C : H surfaces by thermal H (D) atoms. Surface Science. 1994;307-309, Part A:228-34.

[86] Olah GA, Goeppert A, Prakash GKS. Chemical Recycling of Carbon Dioxide to Methanol and Dimethyl Ether: From Greenhouse Gas to Renewable, Environmentally Carbon Neutral Fuels and Synthetic Hydrocarbons. The Journal of Organic Chemistry. 2009;74:487-98.

[87] Nevshupa R, Cruz K, Martinez I, Ramos S, Llorente I, Roman E. Triboemission of gases from iron and construction steel: The effect of surface conditions. Tribology International. 2016;97:360--70.

[88] Nevshupa RA, Roman E, de Segovia JL. Contamination of vacuum environment due to gas emission stimulated by friction. Tribology International. 2013;59:23-9.

[89] Nevshupa RA, de Segovia JL, Deulin EA. Outgassing of stainless steel during sliding friction in ultra-high vacuum. Vacuum. 1999;53:295-8.

[90] Peressadko AG, Nevshupa RA, Deulin EA. Mechanically stimulated outgassing from ball bearings in vacuum. Vacuum. 2002;64:451-6.

[91] Řepa P, Orálek D. Outgassing stimulated by deformation. Vacuum. 1999;53:299-302.

[92] Nevshupa R, Ares JR, Fernández JF, del Campo A, Roman E. Tribochemical Decomposition of Light Ionic Hydrides at Room Temperature. The Journal of Physical Chemistry Letters. 2015;6:2780-5.

[93] Adams HL, Garvey MT, Ramasamy US, Ye Z, Martini A, Tysoe WT. Shear-Induced Mechanochemistry: Pushing Molecules Around. The Journal of Physical Chemistry C. 2015;119:7115-23.

[94] Boldyrev VV. Mechanochemistry and mechanical activation of solids. Russian Chemical Reviews. 2006;75:177-90.

[95] Butyagin PY. Problems in mechanochemistry and prospects for its development. Russian Chemical Reviews. 1994;63:965-76.

[96] Varentsov EA, Khrustalev YA. Mechanoemission and mechanochemistry of molecular organic crystals. Russian Chemical Reviews. 1995;64:783-97. 